\title{
A structure-based model for the prediction of protein-RNA binding affinity
}

\author{
CHANDRAN NITHIN, ${ }^{1}$ SUNANDAN MUKHERJEE, ${ }^{1}$ and RANJIT PRASAD BAHADUR \\ Computational Structural Biology Lab, Department of Biotechnology, Indian Institute of Technology Kharagpur, Kharagpur 721302 , India
}

\begin{abstract}
Protein-RNA recognition is highly affinity-driven and regulates a wide array of cellular functions. In this study, we have curated a binding affinity data set of 40 protein-RNA complexes, for which at least one unbound partner is available in the docking benchmark. The data set covers a wide affinity range of eight orders of magnitude as well as four different structural classes. On average, we find the complexes with single-stranded RNA have the highest affinity, whereas the complexes with the duplex RNA have the lowest. Nevertheless, free energy gain upon binding is the highest for the complexes with ribosomal proteins and the lowest for the complexes with tRNA with an average of $-5.7 \mathrm{cal} / \mathrm{mol} / \AA^{2}$ in the entire data set. We train regression models to predict the binding affinity from the structural and physicochemical parameters of protein-RNA interfaces. The best fit model with the lowest maximum error is provided with three interface parameters: relative hydrophobicity, conformational change upon binding and relative hydration pattern. This model has been used for predicting the binding affinity on a test data set, generated using mutated structures of yeast aspartyl-tRNA synthetase, for which experimentally determined $\Delta G$ values of $\mathbf{4 0}$ mutations are available. The predicted $\Delta G_{\text {empirical }}$ values highly correlate with the experimental observations. The data set provided in this study should be useful for further development of the binding affinity prediction methods. Moreover, the model developed in this study enhances our understanding on the structural basis of protein-RNA binding affinity and provides a platform to engineer protein-RNA interfaces with desired affinity.
\end{abstract}

Keywords: protein-RNA interaction; binding affinity; dissociation constant; conformation change; regression model

\section{INTRODUCTION}

Biomolecular assemblies involving proteins and RNAs are essential for many cellular functions, and the stability of these assemblies is mediated by the noncovalent interactions (Pauling and Pressman 1945; Kauzmann 1959; Chothia and Janin 1975; Janin 1995; Draper 1999; Nadassy et al. 1999; Jones 2001; Treger and Westhof 2001; Bahadur et al. 2008). These noncovalent forces are responsible for the binding processes as well as for the folding of the biomolecules; however, specificity plays an important role in the recognition. Although the conformation of the chemical groups, constituting the biomolecules in three dimensions (3D), determine the specificity of binding, the energy required for the biomolecules to adopt this conformation is the determinant factor for the affinity of complex formation and is termed as the free energy of binding. At equilibrium, the change in Gibbs free energy upon binding

\footnotetext{
${ }^{1}$ Present address: Laboratory of Bioinformatics and Protein Engineering, International Institute of Molecular and Cell Biology in Warsaw, PL-02-109 Warsaw, Poland

Corresponding authors: r.bahadur@hijli.iitkgp.ernet.in, ranjitp_ bahadur@yahoo.com

Article is online at http://www.rnajournal.org/cgi/doi/10.1261/rna. 071779.119
}

$(\Delta G)$ can be determined from the reaction kinetics in terms of the dissociation constant $K_{d}$. Although numerous biophysical and biochemical methods are available to determine the $K_{d}$ (and consequently the $\Delta G$ ) values, the gap between the experimentally determined atomic structures of the complexes available in the Protein Data Bank (PDB) (Berman et al. 2002) and their corresponding free energy of binding is still enormous. To bridge this gap, many physics-based methods have been developed to determine the $\Delta G$ values theoretically (Kollman 1993), which are often correlated with their corresponding experimental values when available in the literature (Horton and Lewis 1992; Murphy et al. 1993; Vajda et al. 1994; Janin 1995; Ma et al. 2002; Audie and Scarlata 2007; Su et al. 2009; Kastritis and Bonvin 2010). Although these methods are extensively used on the protein-ligand and on the protein-protein complexes (Ballester and Mitchell 2010; Moal et al. 2011), they are yet to be tested on the protein-RNA complexes. One of the major difficulties in testing them on the protein-RNA

\footnotetext{
(C) 2019 Nithin et al. This article is distributed exclusively by the RNA Society for the first 12 months after the full-issue publication date (see http://rnajournal.cshlp.org/site/misc/terms.xhtml). After 12 months, it is available under a Creative Commons License (Attribution-NonCommercial 4.0 International), as described at http://creativecommons.org/licenses/by-nc/4.0/.
} 
complexes is the scarcity of the available experimental data of protein-RNA binding affinity. However, the growing interest in the field of studying protein-RNA interactions made available a handful of experimentally determined $K_{d}$ values for a diverse set of protein-RNA complexes.

Recently, we have assembled a protein-RNA docking benchmark v2.0, which contains 126 complexes (Nithin et al. 2017) as an update to the $v 1.0$ of protein-RNA docking benchmarks (Barik et al. 2012b; Pérez-Cano et al. 2012; Huang and Zou 2013). Of these complexes, the binding affinity values are available for 40 cases in the literature. The curated data set represents a wide array of biological functions with affinities covering eight orders of magnitude (range between $10^{-4}$ and $10^{-11} \mathrm{M}$ ), as well as four different structural classes. We train a mathematical model to predict the protein-RNA binding affinity using structural and physicochemical parameters of the protein-RNA interfaces derived from this data set. In addition, we have successfully tested this model on a data set of mutated structures of yeast Asp-tRNA synthetase complexed with its cognate tRNA, for which experimental $\Delta G$ values of 40 mutations are available in the literature (Eriani and Gangloff 1999). Our findings will provide a basis for the quantitative description of protein-RNA binding affinity and may further be extended to engineer protein-RNA interfaces with desired affinity. Additionally, the curated data set can be used for further development and testing of algorithms to predict the protein-RNA binding affinity.

\section{RESULTS}

\section{The data set of protein-RNA binding affinity}

The starting point of the present study is the protein-RNA docking benchmark v2.0 compiled by Nithin et al. (2017). We performed an exhaustive literature survey to curate the binding affinity data of the protein-RNA complexes, for which at least one unbound structure is available. The binding affinity data set contains 40 complexes, for which the $K_{d}$ values were determined by any of the six methods described in the Materials and Methods section. For each complex in this data set, we report the following parameters in Table 1: PDB entry code and the chain identifiers for the complex and its constituents, the length of the RNA molecule in the crystal structure and in the solution, the $K_{d}$ value and the derived $\Delta G$, the temperature and the $\mathrm{pH}$ at which the measurements were done, the experimental methodologies used, and the references reporting the publications. In addition, we also report the values of interface area $(B)$, free energy gain upon binding of the partner molecules, c-rmsd, p-rmsd, i-rmsd, and the flexibility of the interface.

There are different data sets available for protein-RNA binding affinity values curated by multiple groups (Nithin et al. 2018). With 73 cases, the first data set of affin- ity values was developed in 2013 by the Liu group (Yang et al. 2013). The PDBBind data set developed by the Wang group reports affinity values for six protein-RNA complexes (Liu et al. 2015). Similarly, the Bahadur group had curated the data set of affinity values for alanine substitutions in protein components of protein-RNA complexes, which reports 94 experimental affinity values for 14 native structures (Barik et al. 2016). This data set was later expanded by the Deng group to include 49 RNP complexes (Pan et al. 2018), which reports 334 experimental affinity values. More recently, the Mitchell and Zhu groups developed the dbAMEPNI data set, which reports experimentally determined affinity values for 51 protein-RNA complexes (Liu et al. 2018) and for 193 alanine substitutions in these RNA-binding proteins. In the current study, we have used the data set of affinity values curated for complexes available in the protein-RNA docking benchmark, which is highly nonredundant, making the choice justified.

\section{Experimental techniques used to measure the affinity values}

An important aspect to be considered about the binding affinity data set is the methodological difference among different experimental techniques used for affinity measurements (Kastritis and Bonvin 2013). Protein-RNA binding affinity is highly dependent on temperature, $\mathrm{pH}$, and ionic strength, as well as the presence of a high concentration of other macromolecules. This has been carefully checked for all the cases present in this data set and is reported in Table 1. The affinity values reported in Table 1 were measured by the following experimental methods: EMSA (Ryder et al. 2008), filter binding assay (Rio 2012), fluorescence spectroscopy (Vivian and Callis 2001), kinetic study (Goodrich and Kugel 2015), ITC (Feig 2009), and SPR (Katsamba et al. 2002). All the experiments that measured the reported dissociation constants in the present data set have been performed in the temperature range between $273 \mathrm{~K}$ and $338 \mathrm{~K}$.

In 13 cases, the $K_{d}$ values were determined by EMSA, which is routinely used to visualize the protein-RNA interactions (Ryder et al. 2008). This method relies on the electronic property of the RNA surface, which helps them to migrate toward an anode upon application of an electric field in an agarose or polyacrylamide gel matrix. The average $K_{d}$ value determined by EMSA is in the micromolar range, although it reports both high affinity $\left(K_{d}=5.4 \times\right.$ $\left.10^{-11} \mathrm{M}\right)$ in the helicase dbpA-23S rRNA fragment complex (Hardin et al. 2010) and low affinity $\left(K_{d}=1.0 \times 10^{-6} \mathrm{M}\right)$ in elongation factor Sel B and the RNA complex (Yoshizawa et al. 2005). The dissociation constants measured by EMSA were at different temperatures, and the average $\Delta G$ is $-10.55 \mathrm{kcal} / \mathrm{mol}$ (Table 1 ). EMSA captures more stable interactions, which can tolerate electrophoresis 


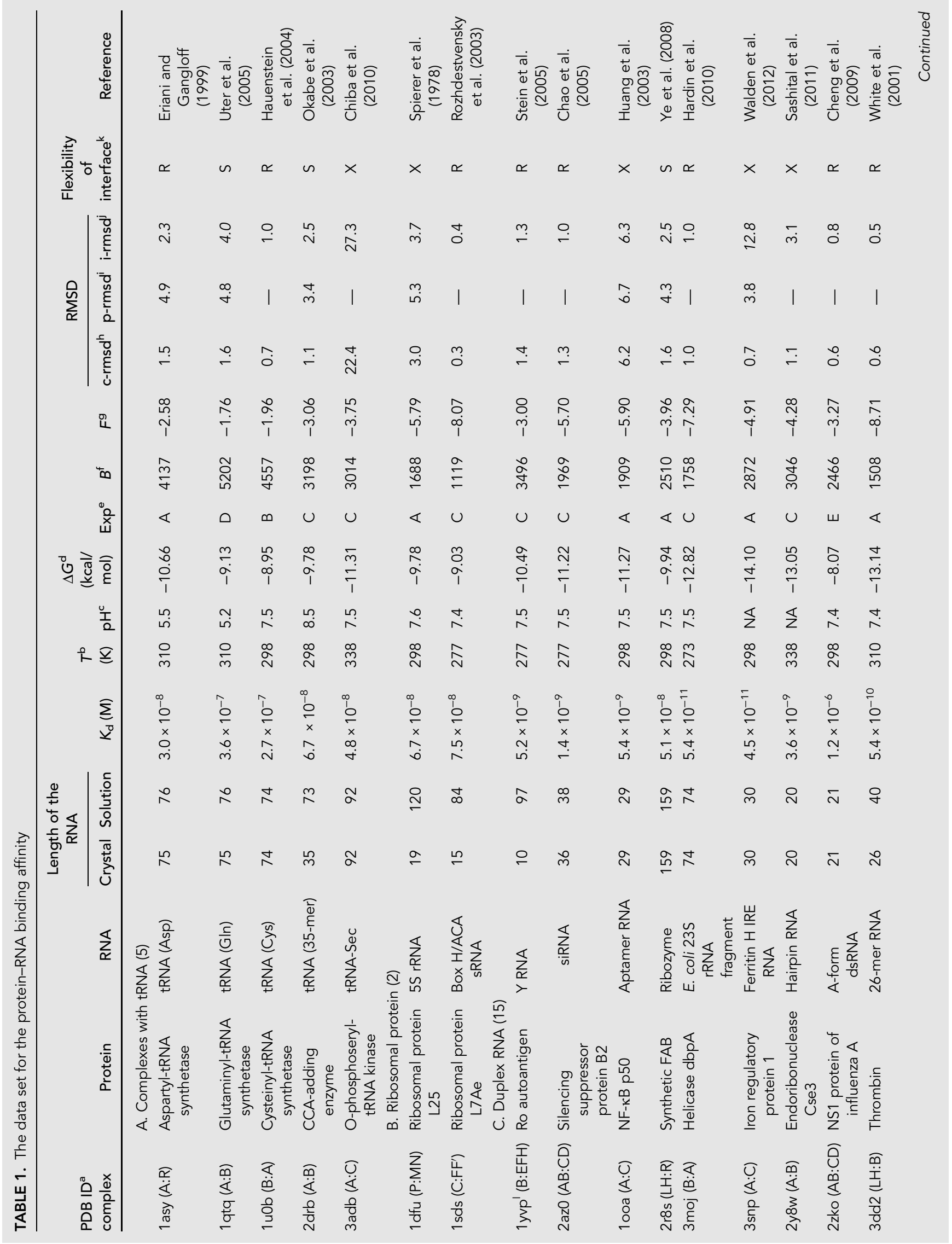




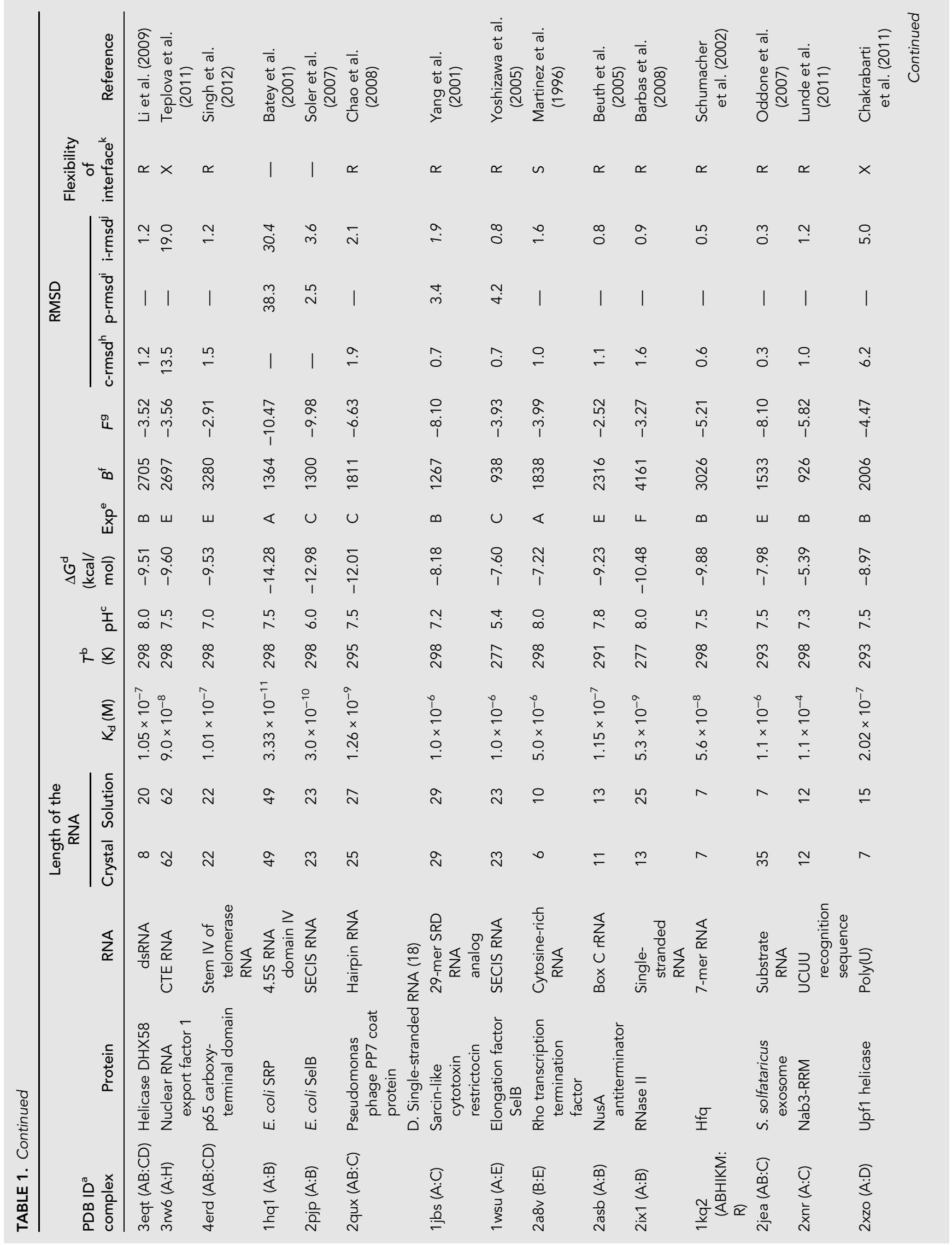




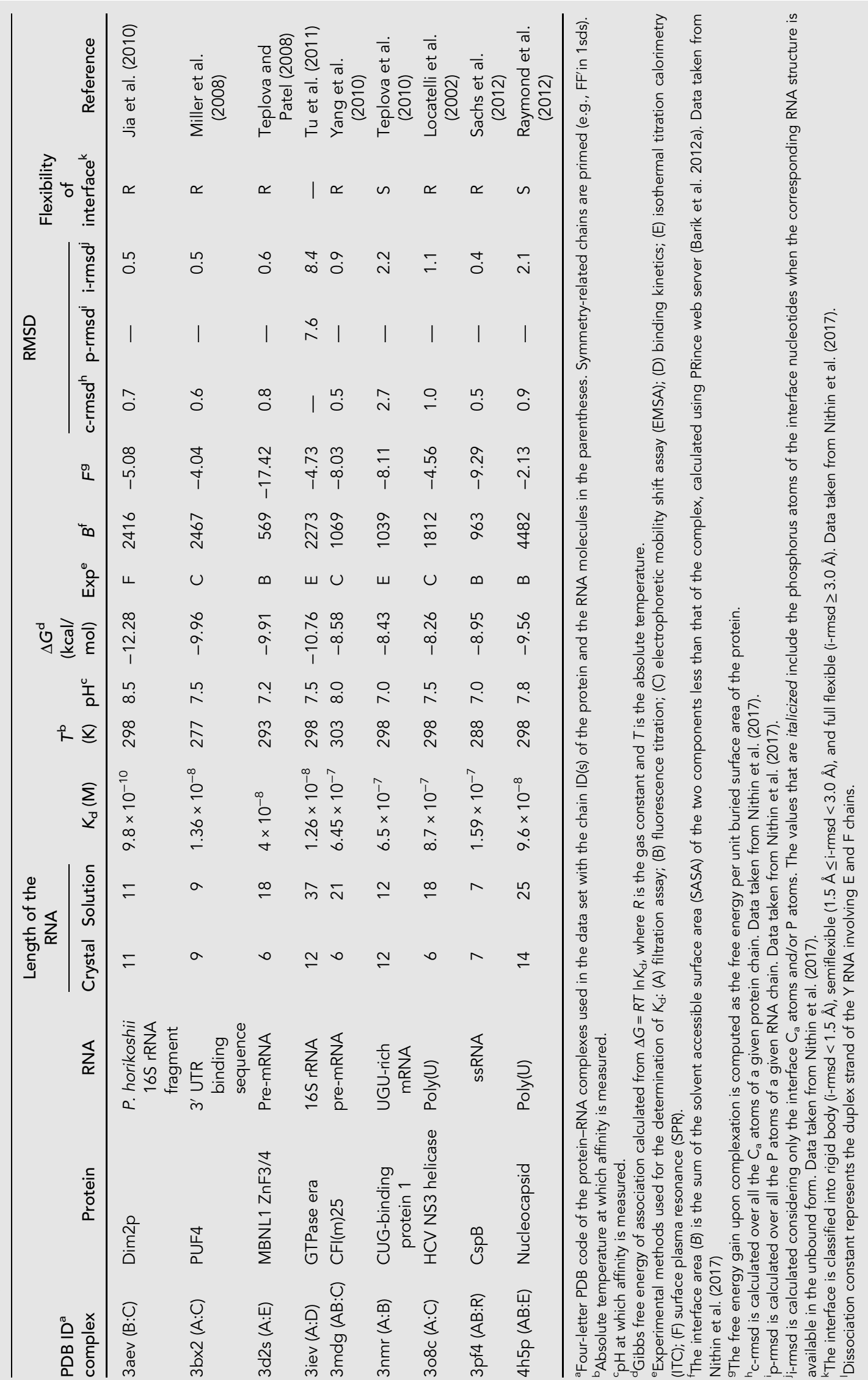


conditions and heat generated during the process (Hellman and Fried 2007).

Fluorescent spectroscopy (Vivian and Callis 2001) makes use of either the intrinsic tryptophan fluorescence (Ghisaidoobe and Chung 2014) or fluorophore-labeled oligonucleotide probes (Pagano et al. 2011) to quantitatively monitor the protein-nucleic acid interactions. This method is the second major method that reports nine $K_{d}$ values with an average of $1.25 \times 10^{-5} \mathrm{M}$, and the corresponding average for $\Delta G$ is $-8.81 \mathrm{kcal} / \mathrm{mol}$. The value ranges from $1.1 \times 10^{-4} \mathrm{M}$ in the complex between Nab3-RRM and the UCUU recognition sequence (Lunde et al. 2011) to $4.0 \times 10^{-8} \mathrm{M}$ in the complex between the $\mathrm{ZnF}$ domain and pre-mRNA (Teplova and Patel 2008). The affinity measurements by the fluorescence titration method could be affected by the use of a labeling that may alter the binding behavior of the complex (Klotz 1985).

Filter binding assay (Rio 2012) is the third major method that reports $K_{d}$ values for eight complexes. This methodology is based on the assumption that proteins bind to nucleic acids, and if a protein is associated with a nucleic acid, then the complex can also be retained on a nitrocellulose filter (Hall and Kranz 1999). This method is fully informative when there is a single binding site, but it fails at the presence of multiple binding sites. The average $K_{d}$ value reported by this method is $6.44 \times 10^{-7} \mathrm{M}$ (corresponding average $\Delta G$ value is $-11.30 \mathrm{kcal} / \mathrm{mol}$ ) with a range from $5.0 \times 10^{-6} \mathrm{M}$ in the complex between the Rho transcription termination factor and cytosine-rich RNA (Martinez et al. 1996) to $3.33 \times 10^{-11} \mathrm{M}$ in the complex between SRP and 4.5S RNA (Batey et al. 2001). These values were measured either at $298 \mathrm{~K}$ or at $310 \mathrm{~K}$. The association between the protein and the nucleic acid must be tight enough to survive the filtration, and the protein must be able to retain the bound nucleic acid when it is in turn bound to the filter (Oehler et al. 1999).

ITC measures the heat taken up or given off during interaction between protein and RNA (Feig 2009). The enthalpy changes associated with the binding are measured by calorimetry, which makes it the only method available for directly determining the thermodynamic parameters associated with an interaction (Ladbury and Chowdhry 1996). ITC was used in the determination of $K_{d}$ values for seven complexes with an average $K_{d}$ of $4.67 \times 10^{-7} \mathrm{M}$, and the values range from $1.2 \times 10^{-6} \mathrm{M}$ in the complex between NS1 and dsRNA (Cheng et al. 2009) to $1.26 \times 10^{-8} \mathrm{M}$ in the complex between GTPase ERA and 16S rRNA (Tu et al. 2011). Even though ITC has high sensitivity, the extraction of heat effects of complex formation can be challenging under certain conditions. For instance, when the association of protein and RNA exhibits small binding enthalpy, the signal-to-noise ratio is relatively low. Similarly, when the complex formation is a rather slow process, the kinetically low process can get neglected ( $\mathrm{Du}$ et al. 2016).

The other two methods, SPR and kinetic study, report $K_{d}$ values for two $\left(9.8 \times 10^{-10} \mathrm{M}\right.$ and $\left.5.3 \times 10^{-9} \mathrm{M}\right)$ and one $\left(3.6 \times 10^{-7} \mathrm{M}\right)$ complex, respectively. SPR is an optical technique that measures the refractive index near the surface of the sensor (Yang et al. 2008). SPR (Biacore) is able to detect more transient and less stable interactions in the solution phase when the ligand molecule is provided at a very low concentration ranging from picomolar to nanomolar (Katsamba et al. 2002). However, the measurements performed by SPR could be affected by mass transfer limitations and the heterogeneity of the binding surface (Schuck and Zhao 2010).

\section{Affinity in different structural classes}

In the present data set, nine out of 40 complexes have both the protein and the RNA components in their free forms. Table 2 represents the data set divided into four structural classes as provided in the protein-RNA docking benchmark: (A) complexes with tRNA, (B) complexes with ribosomal protein, (C) complexes with duplex RNA, and (D) complexes with single-stranded RNA. They represent $12.5 \%, 5 \%, 37.5 \%$, and $45 \%$ of the cases, respectively. In addition, Table 2 provides the mean value and the standard deviation for $\Delta G, B$, and $i$-rmsd in each class. All the

TABLE 2. Affinity and structural classes of the complexes

\begin{tabular}{lcccc}
\hline Structural class $^{\mathrm{a}}$ & Number of complexes & Mean $( \pm \mathrm{SD}) \Delta G^{\mathrm{b}} \mathrm{kcal} / \mathrm{mol}$ & Mean $( \pm \mathrm{SD}) \mathrm{B}^{\mathrm{c}}\left(\AA^{2}\right)$ & ${\text { Mean }( \pm \mathrm{SD}) \mathrm{i}-\mathrm{rmsd}{ }^{\mathrm{d}}(\AA)}$ \\
\hline A. Complexes with tRNA & 5 & $-10.0(0.9)$ & $4022(823)$ & $7.4(10)$ \\
B. Ribosomal proteins & 2 & $-9.4(0.4)$ & $1404(285)$ & $2.1(1.7)$ \\
C. Duplex RNA & 15 & $-11.5(1.8)$ & $2313(681)$ & $5.8(8.3)$ \\
D. Single-stranded RNA & 18 & $-9.0(1.5)$ & $1950(1087)$ & $1.7(1.9)$ \\
All & 40 & $-10.1(1.9)$ & $2322(1135)$ & $3.2(6.7)$ \\
\hline
\end{tabular}

${ }^{a}$ The structural class for protein-RNA complexes is taken from Bahadur et al. (2008).

bThe mean $\Delta G$ value in each structural class is calculated from the reported $K_{d}$ value using Equation 6 described in the Materials and Methods section.

'The average interface area (B) in each structural class.

'The average i-rmsd in each structural class. 
structures reported in this data set are of medium affinity class as described in the affinity benchmark of protein-protein complexes by Kastritis et al. (2011).

The structural class A contains five complexes with aminoacyl tRNA synthetases and their corresponding tRNAs. The $K_{d}$ is in the range from $3 \times 10^{-8} \mathrm{M}$ to $3.6 \times 10^{-7} \mathrm{M}$. The average $\Delta G$ in this class is $-9.97 \mathrm{kcal} / \mathrm{mol}$, and the corresponding average interface area $(B)$ is $4022 \AA^{2}$. The data set contains only two $K_{d}$ values for the class $B$ complexes involving ribosomal protein and rRNA. For both of them, the dissociation constant is $\sim 7 \times 10^{-8} \mathrm{M}$. The average $\Delta G$ in this class is $-9.4 \mathrm{kcal} / \mathrm{mol}$, and the average $B$ is 1404 $\AA^{2}$. Class $C$, complexes with duplex RNA, exhibits a wide $K_{d}$ range from $1.2 \times 10^{-6} \mathrm{M}$ to $3.33 \times 10^{-11} \mathrm{M}$ with an average of $1.04 \times 10^{-7} \mathrm{M}$ (corresponding average $\Delta G$ value is $-11.47 \mathrm{kcal} / \mathrm{mol}$ ). In this class, the highest affinity is found in the complex between the SRP and 4.5S RNA $\left(K_{d}\right.$ is $\left.3.33 \times 10^{-11} \mathrm{M}\right)$. Here, the minor groove of $4.5 \mathrm{~S}$ RNA recognizes the $M$ domain of SRP and the recognition is highly sequence-specific (Batey et al. 2001). The buried surface area between the protein and the RNA is $1364 \AA^{2}$ (Fig. 1A) with a fully flexible interface (i-rmsd $d_{\text {RNA }}=30.4 \AA$ ). The average $\Delta G$ in class $C$ complexes is $-11.5 \mathrm{kcal} / \mathrm{mol}$, and the average $B$ is $2313 \AA^{2}$. Class $D$ involves complexes with single-stranded RNA with a wide $K_{d}$ ranging from 9.80 $\times 10^{-10} \mathrm{M}$ to $1.10 \times 10^{-4} \mathrm{M}$. The average $\Delta G$ is $-8.98 \mathrm{kcal} /$ $\mathrm{mol}$, and the average $B$ is $1950 \AA^{2}$. This structural class contains the lowest affinity complex involving Nab3-RRM and the UCUU recognition sequence $\left(K_{d}\right.$ is $\left.1.1 \times 10^{-4} \mathrm{M}\right)$ in which the protein-RNA recognition process is sequencespecific (Lunde et al. 2011). The buried surface area between the protein and the RNA is very small $\left(926 \AA^{2}\right)$ (Fig. 1B) with a rigid interface (i-rmsd $=1.2 \AA$ ). Table 2 shows that average $\Delta G$ is the highest for complexes involving single-stranded RNA and the lowest for complexes in- volving duplex RNA with significant standard deviation in each class.

\section{Conformational changes and the binding affinity}

Protein-RNA interactions are often associated with conformational changes in which both the protein and the RNA molecules undergo significant rearrangements in their 3D structures upon binding (Ellis et al. 2007). At the protein side, the frequent changes include the sidechain rotation, small adjustments of the main chain, or large movements of the domains. Nevertheless, large domain movement exhibited in the ribosomal protein L1-mRNA complex (Tishchenko et al. 2006) or the transition of the polypeptide chain from disordered to ordered state exhibited in the P22 N-peptide bound to boxB RNA (Bahadur et al. 2009) and in the pseudouridine synthase TruB-tRNA complex (Pan et al. 2003) are also associated with RNA binding. Being more flexible than protein, RNA undergoes larger conformational changes than its partner protein at the protein-RNA binding site (Barik et al. 2012b). The data set displays examples with varying flexibility at the protein-RNA binding sites. While at one end it has a full flexible protein exemplified in the O-phosphoseryl-tRNA kinase-tRNA-Sec complex (i-rmsd: $27.3 \AA$; PDB ID: $3 A D B$ ), at the other end it has a rigid complex formed between exosome and substrate RNA (irmsd: $0.3 \AA$; PDB ID: 3IEV). The corresponding $\Delta G$ values are $-11.31 \mathrm{kcal} / \mathrm{mol}$ and $-7.98 \mathrm{kcal} / \mathrm{mol}$, respectively, with a significant difference in their interface area, which are $3014 \AA^{2}$ and $1533 \AA^{2}$, respectively (Table 1 ). Average i-rmsd is the lowest in the complexes with single-stranded RNA and the highest in the complexes with double-stranded RNA (Table 2); however, the overall correlation with the $\Delta G$ is poor (Table 3 ).
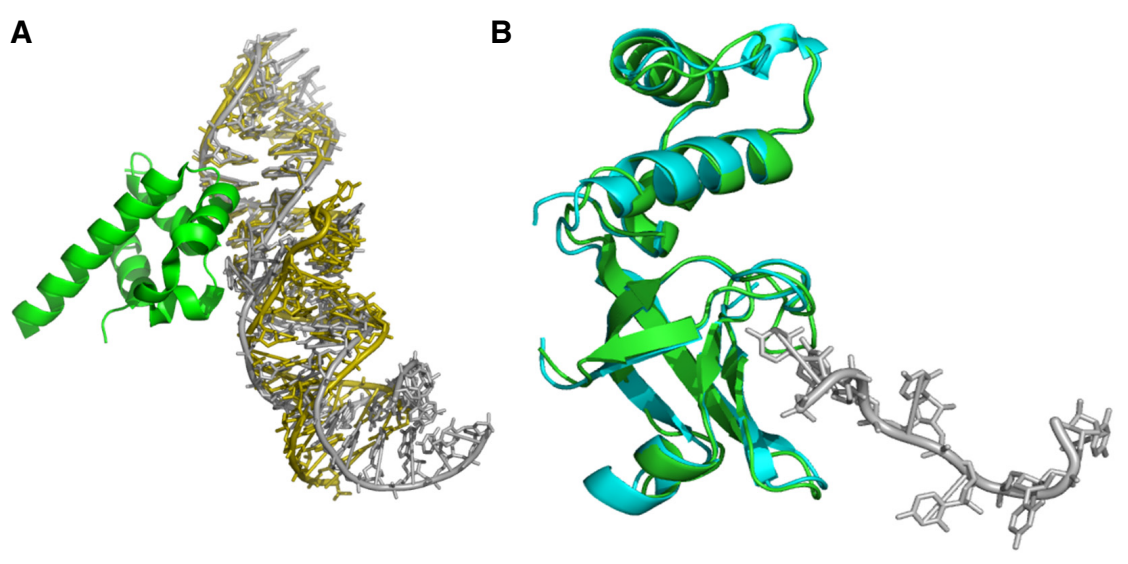

FIGURE 1. Test cases in the protein-RNA affinity data set. (A) Structure of an SRP in complex with 4.5 S RNA (PDB ID: $1 \mathrm{HQ} 1$; structural class $C$ ), and (B) structure of the Rho transcription termination factor in complex with cytosine-rich RNA (PDB ID: 2A8V; structural class D). In each case, the bound form of the protein is in green, and the unbound form is in cyan. The bound form of RNA is in gray, and the unbound is in olive.

\section{Variable length of the RNA and affinity measurements}

For each complex, Table 1 shows the length of the RNA in the crystal structure, as well as in the solution prepared for the $K_{d}$ measurement. In mostcases, the length of the RNA in the solution used for determining the $K_{d}$ values are different from those available in the crystal structures. In the structural class $A$, in all but one case, the length of the RNAs from crystal and from solution is identical. This exception is found in the complex CCA-adding enzyme bound to 35-mer tRNA. Here, the partial tRNA used in the crystal is a synthetic construct (Tomita et al. 2006). In the structural class $B$, the 
TABLE 3. Pearson correlation coefficient between binding affinity and structural parameters

\begin{tabular}{lccc}
\hline & \multicolumn{3}{c}{ Correlation of $\Delta G$ with } \\
\cline { 2 - 4 } Class $^{\mathrm{a}}$ & Interface area $(B)\left(\AA^{2}\right)$ & c-rmsd & i-rmsd \\
\hline A (5) & 0.72 & -0.76 & -0.59 \\
B (2) & - & - & - \\
C (15) & 0.49 & 0.26 & -0.37 \\
D (18) & -0.50 & 0.002 & -0.16 \\
Overall (40) & -0.12 & -0.12 & -0.41 \\
\hline
\end{tabular}

${ }^{a}$ Affinity values are divided into different structural classes according to Bahadur et al. (2008). The values in the parentheses represent the number of complexes. Structural class B has only two complexes and thus is removed from the statistics.

RNA molecules in the crystal are shorter than those in the solution for $K_{d}$ measurements. In the structural class $C$, significant RNA length variability is observed in three out of 15 cases. In the structural class $D$, significant RNA length variability is observed in nine out of 18 cases. In all of these cases, where the length variation exists, most of the crystal structures contain a part of the full-length RNA or synthetic RNA constructs, which are generally biologically irrelevant. In such cases, to predict the binding affinity theoretically, predictors should start with the longer RNA and model its conformation (Sim et al. 2012).

\section{Mathematical model for the prediction of binding affinity}

The data set of affinity values curated in this study has been used to generate a regression model to predict the binding affinity from various structural and physicochemical parameters (Supplemental Table S1). We have developed mathematical models as described in the Materials and Methods section using Eureqa (Schmidt and Lipson 2009). Models with $R^{2}$ (the coefficient of determination) below 0.8 were discarded. The models fitted with the lowest error are selected and listed in Supplemental Table S2. The best fit model with minimum values for maximum error reported in the regression fitting is

$$
\begin{aligned}
\Delta G_{\text {empirical }}= & \frac{86.4 \times \sin (86.8 \times \mathrm{i}-\mathrm{rmsd})-236-5.95 \times \mathrm{i}-\mathrm{rmsd}}{f_{n p_{p}}} \\
& -5.43-1.94 \times d r^{2} \times \sin \left(f_{n p_{p}}\right) \times \sin (d r \\
& +270 \times \mathrm{i}-r m s d),
\end{aligned}
$$

where $f_{n p_{p}}$ is the fraction of nonpolar interface atoms on the protein side. The parameter dr quantifies the relative hydration of interfaces. It is defined as the ratio of the average distance of interface waters to the average distance of interface atoms (Barik and Bahadur 2014). All the distances were measured from the center of mass of the interface.
The above model has a goodness of fit $\left(R^{2}\right)$ value of 0.92 and a correlation coefficient of 0.96 , with a mean absolute error of 0.27 and mean squared error of 0.30 . The goodness of fit is represented graphically as a plot of experimental and predicted values of $\Delta G$ (Fig. 2).

The intrinsic variability embedded in different experimental techniques for measuring the binding affinity may account for the difference between the predicted and the experimental values. To test the validity of the model building process, different models were trained on data derived from a single experimental method. The experimental methods A, B, C, and E were used to train the models. The number of data points available for experimental methods $D$ and $F$ was not sufficient to train mathematical models. Equations 2 to 5 represent the best models from training using data from $A, B, C$, and $E$, respectively:

$$
\begin{aligned}
& \Delta G_{\text {empirical }}=10.5 \times d r+\frac{-624}{f_{n p_{p}}}-7.38-0.0221 f_{n p_{p}} \\
&-0.231 \times \mathrm{i}-r \mathrm{rmsd}, \\
& \Delta G_{\text {empirical }}=163 \times d r+0.169 \times \mathrm{i}-\mathrm{rmsd}-69 \\
&-0.000157 \times f_{n p_{p}}^{2}-122 \times d r \\
& \times \sin (d r), \\
& \Delta G_{\text {empirical }}= 7.33 \times d r+2.85 \times \mathrm{i}-\mathrm{rmsd} \\
&+\frac{256-161 \times \mathrm{i}-\mathrm{rmsd}}{f_{n p_{p}}}-22.4 \\
&-1.74 \sin \left(\frac{1232.95}{f_{n p_{p}}}\right), \\
& 98.7+\frac{2910.18}{f_{n p_{p}}}-0.14 \times \mathrm{i}-\mathrm{rmsd} \\
&-0.967 \times f_{n p_{p}}-1.17 \cos (3.86 \\
& \times G_{\text {empirical }}\times \mathrm{i}-\mathrm{rmsd}) .
\end{aligned}
$$

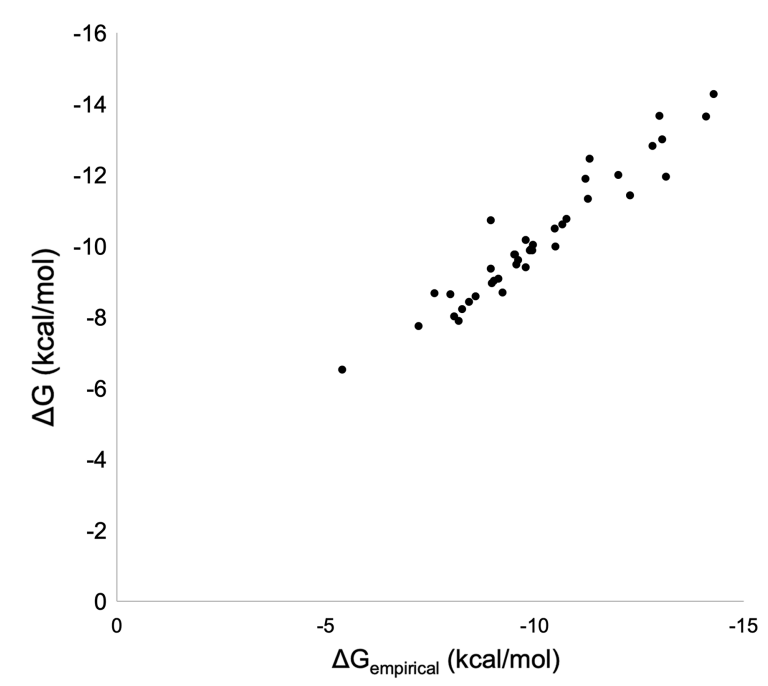

FIGURE 2. Observed $\Delta G$ (in $\mathrm{kcal} / \mathrm{mol}$ ) versus predicted $\Delta G_{\text {empirical }}$ (in $\mathrm{kcal} / \mathrm{mol}$ ) for the training data set. 
The models trained were tested on the data set and the results are shown in Figure 3. The variable sensitivity report for all the models is available in Supplemental Table S3.

\section{Validation of the mathematical model on the test data set}

The model was tested on a data set of $\Delta G$ values curated from literature for yeast aspartyl-tRNA synthetase (AspRS) (Eriani and Gangloff 1999). Experimentally determined

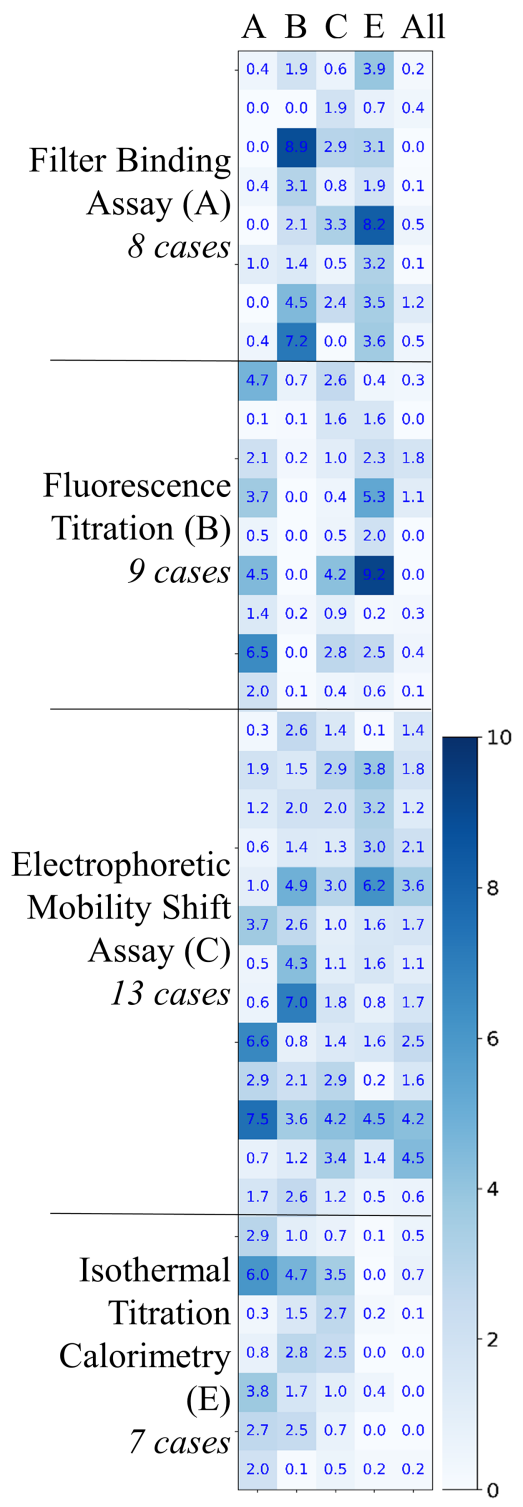

FIGURE 3. A comparison of predictions for models trained on four data sets segregated based on the experimental method as well as the overall training data set. The four segregated data sets include $K_{d}$ values determined by filtration assay $(A)$, fluorescence titration $(B)$, EMSA $(C)$, and ITC $(E)$. The number of data points available for $K_{d}$ determined by two experimental methods, binding kinetics $(D)$ and SPR $(F)$, was not sufficient to train independent mathematical models.

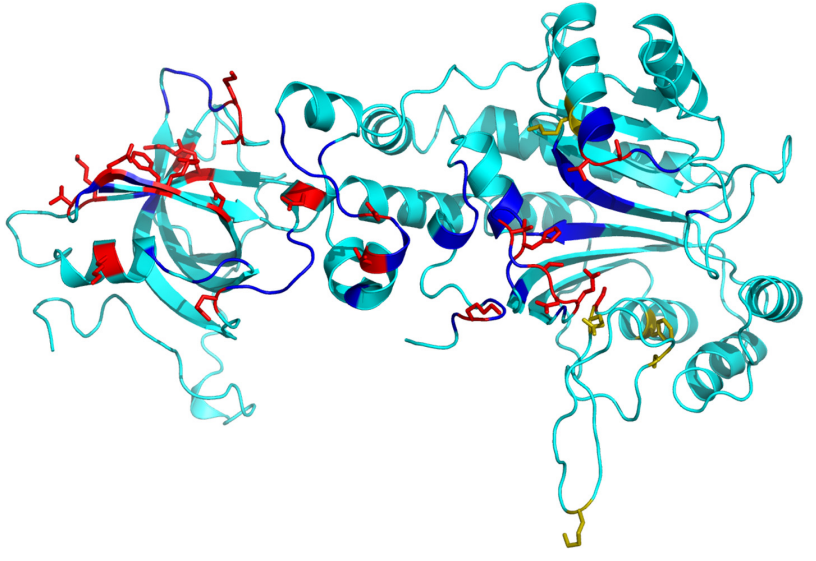

FIGURE 4. Mutated residues in yeast Asp-tRNA synthetase (PDB ID: 1ASY). The interface and the noninterface residues are shown in blue and cyan, respectively. The residues mutated at the interface are shown in red, whereas those at the noninterface region are shown in olive.

$\Delta G$ values for 40 mutations are available for this complex. Yeast AspRS (PDB ID: 1ASY) representing the various mutated residues at interface and noninterface regions is shown in Figure 4. We modeled each of these mutated structures using the native structure as the template. The various structural and physicochemical parameters were calculated for the mutated structures and the $\Delta G_{\text {empirical }}$ values were calculated using the developed model (Supplemental Table S4). The predicted $\Delta G_{\text {empirical }}$ and experimental $\Delta G$ are presented as a scatter plot in Figure 5. The standard error, the mean absolute error, and the percentage relative error observed in this prediction are $1.69 \%$, $1.42 \%$, and $16.95 \%$ (Supplemental Table S4), respectively.

\section{DISCUSSION}

The availability of experimental binding affinity values facilitates correlating them with the structural data available from the 3D structure determination methods. The binding affinity measures the strength of the association between the biomolecules, and because of the difficulty to measure them directly from the experiments in some specific systems, efforts have been made to estimate them from the correlation derived from the structural data. This effort is very successful in the case of protein-protein complexes correlating the binding free energy with the buried surface area (Chothia and Janin 1975; Guharoy and Chakrabarti 2005). The affinity benchmark for protein-protein complexes (Kastritis et al. 2011; Vreven et al. 2015) facilitates the progress of the theoretical models that uses 3D atomic structures to predict the binding free energy. This was started almost 29 years ago by Horton and Lewis (1992), with a handful of experimental dissociation constants curated from the literature. Since then, many computational methods have been developed based on 


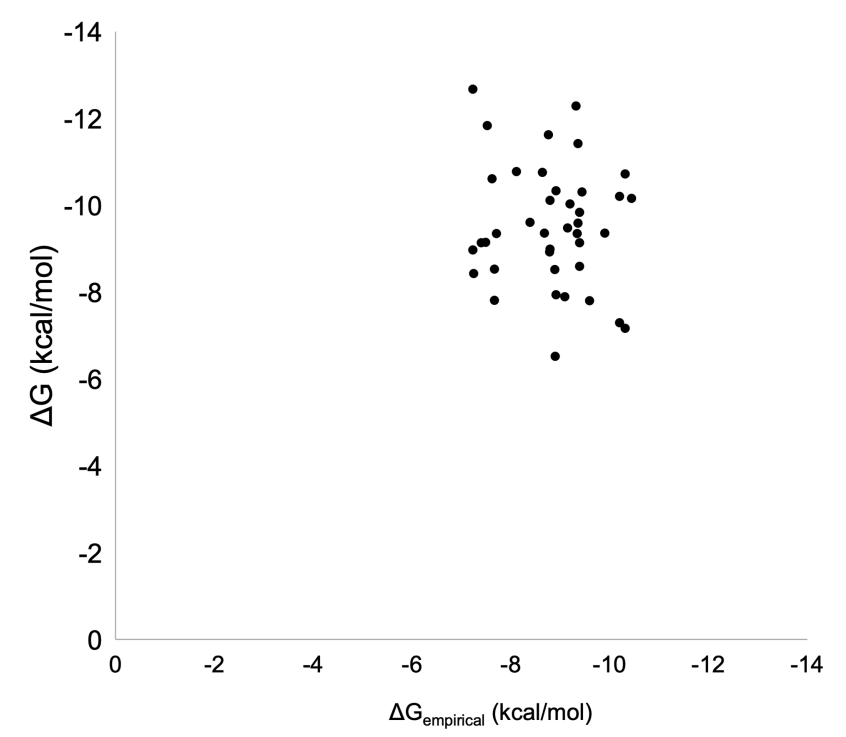

FIGURE 5. Observed $\Delta G$ (in $\mathrm{kcal} / \mathrm{mol}$ ) versus predicted $\Delta G_{\text {empirical }}$ (in $\mathrm{kcal} / \mathrm{mol}$ ) for the substitutions in yeast Asp-tRNA synthetase.

empirical, semi-empirical, or knowledge-based approaches, which predict the binding affinity of protein-protein (Baker and Murphy 1998; Ma et al. 2002; Audie and Scarlata 2007; Kastritis et al. 2011; Tian et al. 2012; Janin 2014; Xue et al. 2016), protein-ligand (Böhm 1994; Eldridge et al. 1997; Mitchell et al. 1999; Gilson and Zhou 2007; Kim and Skolnick 2008; Ballester and Mitchell 2010), and protein-DNA complexes (Selvaraj et al. 2002; Zhang et al. 2005) with varied success. However, because of lack of availability of data, implementation of these methods on protein-RNA complexes is still in its infancy (Yang et al. 2014). The success of all these binding affinity prediction methods partially depends on the quality of the data, which can often be contaminated by incorrect $K_{d}$ values or by the association of $K_{d}$ with incorrect PDB entries due to human error during the literature search. However, even for a high-quality data set, these methods fail to predict the binding affinity correctly because of the lack of accountability for the conformational changes during the binding process.

In this current study, we have developed a structurebased mathematical model for the prediction of proteinRNA binding affinity values. The model was trained on a curated data set of protein-RNA binding affinity available in the literature. In addition, the model was further validated on a protein-RNA complex, for which the binding affinity values of 40 mutations are available in the literature. The affinity benchmark for the protein-protein complexes includes 179 entries (Vreven et al. 2015); however, because of the scarcity of data on protein-RNA complexes, we are restricted here to only 40 entries. Our data set is not only diverse in terms of the RNA structural classes with complexes involving tRNA and ribosomal RNA to duplex and single-stranded RNA, but also diverse in terms of the partners' affinity with $K_{d}$ ranging between $10^{-4} \mathrm{M}$ and $10^{-11}$ $M$. This data set also represents a wide variety of complexes, resembling rigid body, semiflexible, and full flexible based on the conformational changes upon complex formation (Bahadur et al. 2008).

In the present data set of protein-RNA binding affinity, the linear correlations (Pearson correlation coefficient $r$ ) between $\Delta G$ and $\mathrm{i}$-rmsd and between $\Delta G$ and $\mathrm{p}$-rmsd are mediocre, -0.41 and -0.51 , respectively. However, there is no observable correlation between $\Delta G$ and interface area $(B)$ and between $\Delta G$ and c-rmsd for the entire data set (Table 3). In the unbound-unbound class, there exists a good correlation between $\Delta G$ and i-rmsd ( $r=$ -0.91). Except in class A, a mixed correlation is observed between the affinity and the structural parameters among different structural classes. We have calculated the free energy gain upon complex formation (the free energy per unit buried surface area of the protein-RNA complex), which is $-5.7 \mathrm{cal} / \mathrm{mol} / \AA^{2}$ for the entire data set (Table 2). This gain is maximum for the complexes with ribosomal proteins $\left(-7.0 \mathrm{cal} / \mathrm{mol} / \AA^{2}\right)$ and minimum for the complexes with tRNA $\left(-2.7 \mathrm{cal} / \mathrm{mol} / \AA^{2}\right)$. For the other two structural classes, this value is $-5.6 \mathrm{cal} / \mathrm{mol} / \AA^{2}$ (complexes with duplex RNA) and $-5.9 \mathrm{cal} / \mathrm{mol} / \AA^{2}$ (complexes with single-stranded RNA). We did not obtain a correlation coefficient of $>0.73$ in any class or in any temperature category. This may be attributed to the effect of temperature, $\mathrm{pH}$, and ionic strength on the measurement of $K_{\mathrm{d}}$. This is evident in our data set as the temperature, $\mathrm{pH}$, and ionic strength are different for different experimental measurements.

The curated data set was trained to develop a mathematical model to predict the values of binding free energy of protein-RNA complexes from the structural parameters. The mathematical model developed in this study depends on structural and physicochemical parameters of both the bound and the unbound structures, namely, the fraction of nonpolar protein atoms at the interface, the interface rmsd, and the distribution of water molecules at the interface. Previous reports show that these three parameters play crucial roles in determining protein-RNA recognition (Bahadur et al. 2008; Barik and Bahadur 2014; Barik et al. 2015, 2016). Furthermore, these parameters were also used quite efficiently by many research groups to address various issues in macromolecular recognition (Jayaram and Jain 2004; Rodier et al. 2005; Li and Lazaridis 2007; Teyra and Pisabarro 2007; Janin and Bahadur 2008; Reichmann et al. 2008; Hou et al. 2011; Barik and Bahadur 2014; Barik et al. 2015, 2016). For example, they are quite efficient in discriminating the biological interfaces from the crystal contacts in protein-protein complexes (Bahadur et al. 2004; Rodier et al. 2005; Janin et al. 2008; Terribilini 2008; Iwakiri et al. 2012) and are useful in efficient scoring function for macromolecular docking (Chen 
et al. 2004; Zheng et al. 2007; Setny and Zacharias 2011; Tuszynska and Bujnicki 2011; Zhao et al. 2011; Li et al. 2012; Huang et al. 2013, 2016; Huang and Zou 2014) and the prediction of binding affinity and binding hotspots (Yang et al. 2014; Barik et al. 2016; Krüger et al. 2018; Pan et al. 2018). The model depends on the fraction of nonpolar interface area, $f_{n p_{p}}$, which measures the hydrophobicity at the binding sites. It is evident that the protein-RNA binding is often driven by the conformational changes, and the mathematical model includes the effect of conformational flexibility in the empirical estimation of binding free energy. The model has two terms with this parameter. In the first term, the relationship is inverse, and this shows that a highly polar interface is preferred for RNA binding. This is typical of protein-RNA interfaces, as the polar residues contribute significantly to the binding to the negatively charged phosphate of RNA (Bahadur et al. 2008; Barik et al. 2015). Moreover, the nonpolar region of the interface undergoes significant conformational changes and higher changes in accessible surface area (Mukherjee and Bahadur 2018). The dependence of binding affinity on the parameter $d r$ indicates the important role played by the water molecules in protein-RNA recognition (Barik and Bahadur 2014; Barik et al. 2016). The dr values indicate the relative hydration of protein-RNA recognition sites. Previous studies have demonstrated that the water-binding sites at the protein-RNA interfaces vary significantly from the protein-protein interfaces (Rodier et al. 2005; Barik and Bahadur 2014; Mukherjee et al. 2019). The contribution of water-mediated interactions at the proteinRNA interfaces is significantly higher than at the protein-protein interfaces, and a substantial amount of these interactions are mediated by the $2^{\prime} \mathrm{OH}$ group of the ribose sugar. The mathematical model trained in this study shows that the " $d r$ " values contribute significantly to the $\Delta G_{\text {empirical }}$ values. This can be attributed to the higher number of water-mediated interactions at the proteinRNA interface.

The model was tested on AspRS (PDB ID: 1ASY), for which experimentally determined affinity values of $40 \mathrm{mu}$ tations are available (Eriani and Gangloff 1999), which were not used in the training data set. Of these 40 mutations, 29 are single, 10 are double, and one is a triple mutant (Supplemental Table S4). All the affinity values for the native and mutant structures were measured using nitrocellulose binding assay (Eriani and Gangloff 1999). The majority (35) of these mutations are at the interface, whereas only five are at the noninterface region. Our model predicted the affinity values of 29 (75\%) mutants with an absolute error of $<2 \mathrm{kcal} / \mathrm{mol}$. In the case of eight mutants, the absolute error is within a limit of $3.5 \mathrm{kcal} / \mathrm{mol}$. The remaining two cases, in which the absolute error is $>3.5$ $\mathrm{kcal} / \mathrm{mol}$, are double mutants at the interface. In these two cases, the $\Delta \Delta G$ values are significantly higher, 2.68 and $2.97 \mathrm{kcal} / \mathrm{mol}$.
The different amino acid substitutions in AspRS were at four different binding regions: the terminal A binding region, the acceptor arm binding region, the anticodon loop binding region and the central core binding region (Eriani and Gangloff 1999). The terminal A binding region does not influence the binding of tRNA to AspRS in the ground state and is involved in acylation. The prediction model shows the lowest root mean squared error (RMSE)— $0.83 \mathrm{kcal} / \mathrm{mol}$-for these cases. The predicted values in substitutions on the anticodon binding region and central core binding region show comparable RMSEs with $1.99 \mathrm{kcal} / \mathrm{mol}$ and $1.91 \mathrm{kcal} / \mathrm{mol}$, respectively, whereas the predictions for substitutions at the acceptor arm binding region show a slightly lower RMSE of 1.66 $\mathrm{kcal} / \mathrm{mol}$. The predicted values for double substitutions involving both anticodon loop binding and acceptor arm binding regions show the highest RMSE-2.64 kcal/ mol (Supplemental Table S4). While testing the mathematical model using the mutant structures of yeast AspRS, the mean standard error, the mean absolute error, and the mean percentage relative error observed are $1.69 \%, 1.42 \%$, and $16.95 \%$, respectively. However, the correlation coefficient between the experimental $\Delta G$ and predicted $\Delta G_{\text {empirical }}$ values is poor $\left(R^{2}=0.12\right)$. This poor correlation coefficient may be attributed to two reasons: the errors introduced by modeling and the poor estimate of $d r$ values from the modeled complexes. The template-based modeling technique is unable to recapitulate the structural changes introduced by the alanine substitutions (Fiser 2010). The higher RMSE values observed for the double mutants may be attributed to the modeling error. However, for the mutants with higher $\Delta \Delta G$ values, we observe higher relative error in the predicted $\Delta G_{\text {empirical. }}$. The changes in binding affinity can be quantified in terms of $\Delta \Delta G$ and are indicative of the structural changes in the protein that affects the RNA binding. The correlation coefficient between the experimental and predicted $\Delta G$ values is 0.29 for mutants with $\Delta \Delta G \leq 1.5 \mathrm{kcal} / \mathrm{mol}$. To estimate the $d r$ value with better accuracy, we chose a subset of eight mutants with alanine substitutions at the protein-RNA interface with $\Delta \Delta G \leq 2.0$ $\mathrm{kcal} / \mathrm{mol}$ and solvated them. The solvated structures were further minimized and equilibrated and used to estimate the $d r$ values (Supplemental Table S5). The current force fields available for simulations of protein-RNA complexes have their own limitations (Šponer et al. 2018), which might add additional errors to the modeled structures. Despite this, the correlation between experimental $\Delta G$ and predicted $\Delta G_{\text {empirical }}$ values improves from 0.17 to 0.75 for this subset of mutants. Moreover, for this subset of eight mutants, the RMSE values improve from 1.41 $\mathrm{kcal} / \mathrm{mol}$ to $0.51 \mathrm{kcal} / \mathrm{mol}$. The prediction accuracy is very much dependent on the quality and accuracy of the experimental data. The temperature, $\mathrm{pH}$, ionic condition, and intrinsic variability embedded in different 
techniques may also account for the difference between predicted $\Delta G_{\text {empirical }}$ and experimental $\Delta G$ values.

\section{Conclusion}

The protein-RNA binding affinity data set curated in this study contains a wide variety of complexes in terms of their structural classes as well as their cellular functions. Moreover, the complexes have a wide range of affinities in which the dissociation constant spans eight orders of magnitude. This data set should be a valuable resource for the computational structural biologists attempting to predict the binding affinity from atomic structures and will also stimulate the development of novel methods accounting for the flexibility in the assembly formation. The major challenges in making this data set are the paucity of binding affinity data and their reliable curation from the literature. The curated data set of affinity values was used to develop a structure-based mathematical model for predicting the binding affinity of protein-RNA complexes. The model developed in this study is highly accurate and can be deployed for finding the affinity of all known protein-RNA complexes. This model will enhance our understanding of the structural basis of protein-RNA binding affinity and may be valuable to the experimentalists aiming to engineer protein-RNA interfaces with desired affinity.

\section{MATERIALS AND METHODS}

\section{The data set of binding affinity}

The protein-RNA docking benchmark was used to get the data set of protein-RNA complexes for which bound and unbound structures are available (Nithin et al. 2017). The binding affinity values were manually curated from the available literature. The publications available as references for the atomic structures submitted in the PDB were checked for the corresponding $K_{d}$ values. When the values were not found in the primary citation, they were found by conducting an exhaustive search by clicking the button "Search Related Articles in PubMed." The experimental $K_{d}$ values were taken only if the protein from the publication was the same as that in the published crystal structure and if there was a match in the organism name. In most of the cases, when the reported $K_{d}$ values were taken from sources other than the published $X$-ray structure in the PDB, the affinity measurements were done on protein samples or genetic constructs that were different from the X-ray studies and under different experimental conditions. The various experimental methods used to calculate the dissociation constants are the filter binding assay (Rio 2012), EMSA (Ryder et al. 2008), fluorescence spectroscopy (Vivian and Callis 2001), kinetic study (Goodrich and Kugel 2015), ITC (Feig 2009), and SPR (Katsamba et al. 2002). The temperature, $\mathrm{pH}$, and the experimental conditions were recorded for all 40 cases from the same publication if available or from the references or protocols followed by the authors. The Gibbs free energy of dissociation was calculated by taking the temperature stated and using the fol- lowing equation $\left(c^{0}=1 \mathrm{M}\right.$ standard state):

$$
\Delta G=R T * \ln \frac{K_{d}}{c^{0}}
$$

\section{Structural and physicochemical parameters used in the prediction of binding affinity}

The following parameters of protein-RNA interfaces were considered in the prediction model: number of amino acids, number of nucleotides, number of interface water molecules, number of preserved interface waters, number of water bridges, $d r$ (parameter to quantify the dry and wet protein-RNA interfaces), number of hydrogen bonds, fraction of nonpolar area on the protein and the RNA sides, fraction of buried atoms on the protein and the RNA sides, local density (LD) indices on the protein and the RNA sides, number of salt bridges and stacking interactions, shape complementarity index, and gap volume (GV) index. All these parameters are calculated following Barik et al. (2015) and Barik and Bahadur (2014).

The size of the protein-RNA interfaces was estimated by measuring the solvent accessible surface area (SASA) buried in the contact. The interface area $(B)$ is the sum of the SASA of the two components less that of the complex and was calculated using the PRince web server (Barik et al. 2012a). The SASA values were measured with the program Naccess (Hubbard and Thornton 1993), which implements the Lee and Richards (1971) algorithm with a probe radius of $1.4 \AA$ and default group radii:

$$
B=S A S A_{\text {Protein }}+S A S A_{R N A}-S A S A_{\text {Complex }} \text {. }
$$

During complex formation, an atom may lose its SASA completely and thus become fully buried in the interface. Those atoms that lose SASA upon complexation were identified as the interface atoms. The fraction of such buried atoms $\left(f_{b u}\right)$ was calculated at the binding regions on both the protein and the RNA side of the interface using the following equation:

$$
f_{\mathrm{bu}}=\frac{\text { Number of buried interface atoms }}{\text { Total number of interface atoms }} \text {. }
$$

Although $f_{b u}$ measures the compactness of the atomic packing at the interface, the LD index is used to measure the atomic density at each point of the interface (Bahadur et al. 2004). In brief, LD is defined as the mean number of interface atoms that are within $12 \AA$ of another interface atom. If an interface has $N$ atoms, and if $n_{i}$ atoms are within a distance of $12 \AA$ from a given interface atom $i$, the LD for that subunit is calculated as below:

$$
L D=\frac{\sum n_{i}}{N}
$$

Hydrogen bonds ( $\mathrm{H}$-bonds) at the protein-RNA interfaces were calculated using the software HBPLUS (McDonald and Thornton 1994) with default parameters. The salt bridges at protein-RNA interfaces were calculated when the distance between the sidechain nitrogen atoms of positively charged residues and the negatively charged phosphate group of the nucleotides is within $4 \AA$ (Barlow and Thornton 1983; Xu et al. 1997). Stacking interactions at protein-RNA interfaces are usually defined as the $\pi-\pi$ interactions that can occur between the side chains of Tyr, Trp, Phe, His, and the RNA bases. Moreover, the $\pi-\pi$ and $\pi$-cation stacking of Arg through its guanidinium moiety with nucleosides were 
included in the calculation of stacking interactions (Allers and Shamoo 2001). The planes were defined at both sides by considering the atoms constituting the aromatic rings, and the center of the plane was calculated as the midpoint of all these atoms. The cutoff distance between the centers of both the planes was kept at $\leq 5 \AA$, and the dihedral angle between the two planes was constrained to $\leq 30^{\circ}$ (Allers and Shamoo 2001). The stagger angle is defined as the angle between the normal to the first plane and the vector joining the centers of the two planes. The shape correlation index $\left(S_{c}\right)$ (Lawrence and Colman 1993; Allers and Shamoo 2001) was used to quantify the shape complementarity at protein-RNA interfaces. Atomic packing at protein-RNA interfaces was also evaluated using the gap volume index (GV) (Jones and Thornton 1996) given by the following equation:

$$
\text { GV Index }(\text { in } \AA)=\frac{\text { Gap volume between molecules }}{B} \text {. }
$$

The GV for each complex was calculated using the SURFNET program (Laskowski 1995).

The structural parameter $d r$ was used to quantitatively define the distribution of the water molecules at the protein-RNA interface. Briefly, $d r$ is a ratio of the average distance of interface water molecules to the average distance of interface atoms contributed by the protein and the RNA chains. In both cases, distances were measured from the center of mass of the interface:

$d r=\frac{\text { Average distance of water from center of mass of interface }}{\text { Average distance of interface atoms from center of mass of interface }}$

The superposition of the structures was performed using the distance matrix alignment method implemented in the Dali server (Holm and Laakso 2016). The root-mean-squared displacement (rmsd) values were calculated from the interface amino acids and nucleotides after superposing the respective bound and unbound structures of the protein and the RNA components when available in their free form. For each polypeptide chain, c-rmsd was calculated, which is the displacement of all the equivalent $\mathrm{C} \alpha$ atoms between the superposed bound and the unbound proteins. For the RNA chains, the p-rmsd values were calculated in a similar way over the superposed equivalent backbone phosphorus (P) atoms. Interface rmsd (i-rmsd) values were calculated for each complex considering only the equivalent $\mathrm{C} \alpha$ atoms of the interface residues and/or the equivalent $P$ atoms of the interface nucleotides. The different structural and physicochemical parameters used in this study are available in Supplemental Table S1.

\section{Development of the mathematical model for prediction of binding affinity}

The mathematical models were generated using regression analysis following Schmidt and Lipson (2009) implemented in Eureqa software. The different physico- chemical and structural parameters for the protein-RNA complexes were provided as inputs to the software. The data set was split randomly into a training data set and a validation data set by the Eureqa software used in this study. The training set is used to generate and optimize solutions, and the validation set is used to test how well those models generalize to new data. Eureqa also uses the validation data to filter out the best models. The following mathematical operations were applied to the input variables while searching for equations that fit the input data: addition, subtraction, multiplication, division, sine, cosine, and constants. For each pair of variables, the numerical partial derivatives were calculated, and these partial derivatives were used to evaluate the symbolic functions generated in the subsequent steps. Candidate symbolic functions were generated to represent the relationship between different parameters provided as input. Initially, these functions generated were random; however, the subsequent filtering of the generated equations allows them to converge to the mathematical representation of input data. In symbolic regression, many initial random symbolic equations compete to model input data in the most parsimonious way. New equations are formed by recombining previous equations and probabilistically varying their subexpressions. The equations that model the input data well were retained, whereas unpromising solutions were removed. To evaluate the predictive ability, the partial derivatives for each pair of variables were computed for the candidate functions, and cross-validation analysis was performed with the partial derivatives derived from the input data. The best matching equations were selected, and this process was repeated iteratively until the predictive ability of these equations reached sufficient accuracy. The most parsimonious equation generated from this process was returned as the best mathematical model (Fig. 6). For each equation, the predictive ability is measured in terms of goodness of fit $\left(R^{2}\right)$, correlation coefficient, maximum error, mean squared error, and mean absolute error. The equations with $R^{2} \geq 0.80$ were selected as plausible models (Supplemental Table S2). The best fit model was selected from these plausible models, and used for predicting the $\Delta G_{\text {empirical. }}$.
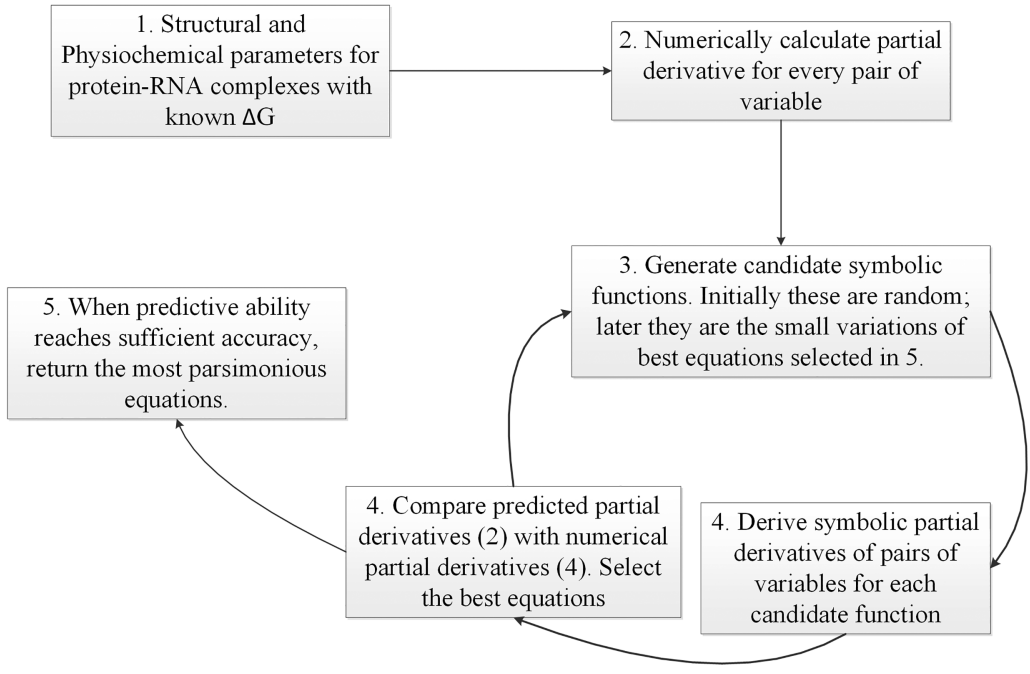

FIGURE 6. Schematic representation of the workflow followed in mathematical modeling for prediction of binding affinity in protein-RNA complexes. 


\section{Validation of the mathematical model on a test data set}

The model was tested on a data set generated using mutated structures of yeast AspRS, which reports experimentally determined $\Delta G$ values of 40 mutations (Eriani and Gangloff 1999). The experimental $K_{d}$ values were used to calculate both $\Delta G$ (using Equation 6) and $\Delta \Delta G$ values of the mutants (using Equation 12):

$$
\Delta \Delta \mathrm{G}=R T \ln \frac{K_{\mathrm{d}} \text { mutant }}{K_{\mathrm{d}} \mathrm{WT}} .
$$

The wild-type PDB structures (PDB ID: 1ASY, IEOV) were used as the templates for modeling all the bound and unbound forms of the proteins with alanine substitutions. The modeling and energy minimization were performed using Modeler (Webb and Sali 2016). The energy-minimized modeled structures are used to calculate structural and physicochemical parameters described above for evaluating the mathematical model for predicting $\Delta G$. For each of the 40 mutant structures, the $\Delta G_{\text {empirical }}$ was calculated using the equation modeled in this study. To evaluate the accuracy of predictions, the RMSE was calculated using the following equation:

$$
\text { RMSE }=\sqrt{\frac{\sum_{i=1}^{N}\left(\Delta G_{\text {empirical } \mathrm{i}}-\Delta G_{\text {observed } \mathrm{i}}\right)^{2}}{N} .}
$$

A subset of eight mutants with $\Delta \Delta G \leq 2.0 \mathrm{kcal} / \mathrm{mol}$ was further optimized using AMBER. The complexes and their unbound structures were solvated using the TIP3P (Sun and Kollman 1995) water model with a truncated octahedral box of $10 \AA$. The solvated structures were energy-minimized for 10,000 cycles with restraint, followed by 10,000 cycles without restraint. The minimized structures were subjected to heating, density equilibration, and short runs of equilibration. The heating was done from $100 \mathrm{~K}$ to $300 \mathrm{~K}$ for 500 psec with restraints on the entire structure. The density equilibration was performed for 500 psec with restraints on the entire structure. The equilibration of the structures was run for four short rounds. The first three rounds of equilibration were run for 200 psec each with main chain atoms constrained. The final round of equilibration was performed for 2 nsec. Amber ff14sb force field (Maier et al. 2015) and $\chi O L 3$ (Banáš et al. 2010; Zgarbová et al. 2011) were used for this study. The minimization was performed using Sander, and the subsequent steps were performed using the CUDA version of PMEMD available in the AMBER package (Götz et al. 2012; Le Grand et al. 2013; Salomon-Ferrer et al. 2013).

\section{SUPPLEMENTAL MATERIAL}

Supplemental material is available for this article.

\section{ACKNOWLEDGMENTS}

We thank Professor Joël Janin of Université Paris Sud, Orsay for the cross-validation of the data set and for the critical reading of the manuscript. C.N. thanks IIT Kharagpur for his fellowship. S.M. thanks the Council of Scientific \& Industrial Research (CSIR)-University Grants Commission (UGC) and IIT Kharagpur for his fellowship. R.P.B. is thankful to CSIR, India.
Received May 4, 2019; accepted August 5, 2019.

\section{REFERENCES}

Allers J, Shamoo Y. 2001. Structure-based analysis of protein-RNA interactions using the program ENTANGLE. J Mol Biol 311: 75-86. doi:10.1006/jmbi.2001.4857

Audie J, Scarlata S. 2007. A novel empirical free energy function that explains and predicts protein-protein binding affinities. Biophys Chem 129: 198-211. doi:10.1016/j.bpc.2007.05.021

Bahadur RP, Chakrabarti P, Rodier F, Janin J. 2004. A dissection of specific and non-specific protein-protein interfaces. J Mol Biol 336: 943-955. doi:10.1016/j.jmb.2003.12.073

Bahadur RP, Zacharias M, Janin J. 2008. Dissecting protein-RNA recognition sites. Nucleic Acids Res 36: 2705-2716. doi:10.1093/nar/ gkn102

Bahadur RP, Kannan S, Zacharias M. 2009. Binding of the bacteriophage P22 N-peptide to the boxB RNA motif studied by molecular dynamics simulations. Biophys J 97: 3139-3149. doi:10.1016/j .bpj.2009.09.035

Baker BM, Murphy KP. 1998. Prediction of binding energetics from structure using empirical parameterization. Methods Enzymol 295: 294-315. doi:10.1016/S0076-6879(98)95045-5

Ballester PJ, Mitchell JB. 2010. A machine learning approach to predicting protein-ligand binding affinity with applications to molecular docking. Bioinformatics 26: 1169-1175. doi:10.1093/ bioinformatics/btq112

Banáš P, Hollas D, Zgarbová M, Jurečka P, Orozco M, Cheatham TE III, Šponer J, Otyepka M. 2010. Performance of molecular mechanics force fields for RNA simulations: stability of UUCG and GNRA hairpins. J Chem Theory Comput 6: 3836-3849. doi:10.1021/ ct100481h

Barbas A, Matos RG, Amblar M, López-Viñas E, Gomez-Puertas P, Arraiano CM. 2008. New insights into the mechanism of RNA degradation by ribonuclease II: identification of the residue responsible for setting the RNase II end product. J Biol Chem 283: 1307013076. doi:10.1074/jbc.M709989200

Barik A, Bahadur RP. 2014. Hydration of protein-RNA recognition sites. Nucleic Acids Res 42: 10148-10160. doi:10.1093/nar/ gku679

Barik A, Mishra A, Bahadur RP. 2012a. PRince: a web server for structural and physicochemical analysis of protein-RNA interface. Nucleic Acids Res 40: W440-W444. doi:10.1093/nar/gks535

Barik A, Nithin C, Manasa P, Bahadur RP. 2012b. A protein-RNA docking benchmark (I): nonredundant cases. Proteins 80: 1866-1871. doi:10.1002/prot.24083

Barik A, Nithin C, Pilla SP, Bahadur RP. 2015. Molecular architecture of protein-RNA recognition sites. J Biomol Struct Dyn 33: 27382751. doi:10.1080/07391102.2015.1004652

Barik A, Nithin C, Karampudi NB, Mukherjee S, Bahadur RP. 2016. Probing binding hot spots at protein-RNA recognition sites. Nucleic Acids Res 44: e9. doi:10.1093/nar/gkv876

Barlow DJ, Thornton JM. 1983. Ion-pairs in proteins. J Mol Biol 168: 867-885. doi:10.1016/S0022-2836(83)80079-5

Batey RT, Sagar MB, Doudna JA. 2001. Structural and energetic analysis of RNA recognition by a universally conserved protein from the signal recognition particle. J Mol Bio/ 307: 229-246. doi:10.1006/ jmbi.2000.4454

Berman HM, Battistuz T, Bhat TN, Bluhm WF, Bourne PE, Burkhardt K, Feng Z, Gilliland GL, lype L, Jain S, et al. 2002. The Protein Data Bank. Acta Crystallogr D Biol Crystallogr 58: 899-907. doi:10 $.1107 /$ S0907444902003451

Beuth B, Pennell S, Arnvig KB, Martin SR, Taylor IA. 2005. Structure of a Mycobacterium tuberculosis NusA-RNA complex. EMBO J 24: 3576-3587. doi:10.1038/sj.emboj.7600829 
Böhm HJ. 1994. The development of a simple empirical scoring function to estimate the binding constant for a protein-ligand complex of known three-dimensional structure. J Comput Aided Mol Des 8: 243-256. doi:10.1007/BF00126743

Chakrabarti S, Jayachandran U, Bonneau F, Fiorini F, Basquin C, Domcke S, Le Hir H, Conti E. 2011. Molecular mechanisms for the RNA-dependent ATPase activity of Upf1 and its regulation by Upf2. Mol Cell 41: 693-703. doi:10.1016/j.molcel.2011.02.010

Chao JA, Lee JH, Chapados BR, Debler EW, Schneemann A, Williamson JR. 2005. Dual modes of RNA-silencing suppression by Flock House virus protein B2. Nat Struct Mol Biol 12: $952-$ 957. doi:10.1038/nsmb1005

Chao JA, Patskovsky Y, Almo SC, Singer RH. 2008. Structural basis for the coevolution of a viral RNA-protein complex. Nat Struct Mol Biol 15: 103-105. doi:10.1038/nsmb1327

Chen Y, Kortemme T, Robertson T, Baker D, Varani G. 2004. A new hydrogen-bonding potential for the design of protein-RNA interactions predicts specific contacts and discriminates decoys. Nucleic Acids Res 32: 5147-5162. doi:10.1093/nar/gkh785

Cheng A, Wong SM, Yuan YA. 2009. Structural basis for dsRNA recognition by NS1 protein of influenza A virus. Cell Res 19: 187-195. doi:10.1038/cr.2008.288

Chiba S, Itoh Y, Sekine S, Yokoyama S. 2010. Structural basis for the major role of O-phosphoseryl-tRNA kinase in the UGA-specific encoding of selenocysteine. Mol Cell 39: 410-420. doi:10.1016/j .molcel.2010.07.018

Chothia C, Janin J. 1975. Principles of protein-protein recognition. Nature 256: 705-708. doi:10.1038/256705a0

Draper DE. 1999. Themes in RNA-protein recognition. J Mol Biol 293: 255-270. doi:10.1006/jmbi.1999.2991

Du X, Li Y, Xia Y-L, Ai S-M, Liang J, Sang P, Ji X-L, Liu S-Q. 2016. Insights into protein-ligand interactions: mechanisms, models, and methods. Int J Mol Sci 17: 144. doi:10.3390/ijms17020144

Eldridge MD, Murray CW, Auton TR, Paolini GV, Mee RP. 1997. Empirical scoring functions: I. The development of a fast empirical scoring function to estimate the binding affinity of ligands in receptor complexes. J Comput Aided Mol Des 11: 425-445. doi:10.1023/A:1007996124545

Ellis JJ, Broom M, Jones S. 2007. Protein-RNA interactions: structural analysis and functional classes. Proteins 66: 903-911. doi:10 $.1002 /$ prot. 21211

Eriani G, Gangloff J. 1999. Yeast aspartyl-tRNA synthetase residues interacting with tRNA(Asp) identity bases connectively contribute to tRNA(Asp) binding in the ground and transition-state complex and discriminate against non-cognate tRNAs. J Mol Biol 291: 761-773. doi:10.1006/jmbi.1999.3012

Feig AL. 2009. Studying RNA-RNA and RNA-protein interactions by isothermal titration calorimetry. Methods Enzymol 468: 409-422. doi:10.1016/S0076-6879(09)68019-8

Fiser A. 2010. Template-based protein structure modeling. Methods Mol Biol 673: 73-94. doi:10.1007/978-1-60761-842-3_6

Ghisaidoobe ABT, Chung SJ. 2014. Intrinsic tryptophan fluorescence in the detection and analysis of proteins: a focus on Förster resonance energy transfer techniques. Int J Mol Sci 15: 2251822538. doi:10.3390/ijms151222518

Gilson MK, Zhou HX. 2007. Calculation of protein-ligand binding affinities. Annu Rev Biophys Biomol Struct 36: 21-42. doi:10.1146/ annurev.biophys.36.040306.132550

Goodrich JA, Kugel JF. 2015. Studying the affinity, kinetic stability, and specificity of RNA/protein interactions: SINE ncRNA/Pol II complexes as a model system. Methods Mol Biol 1206: 165178. doi:10.1007/978-1-4939-1369-5_15

Götz AW, Williamson MJ, Xu D, Poole D, Le Grand S, Walker RC. 2012. Routine microsecond molecular dynamics simulations with
AMBER on GPUs. 1. Generalized born. J Chem Theory Comput 8: 1542-1555. doi:10.1021/ct200909j

Guharoy M, Chakrabarti P. 2005. Conservation and relative importance of residues across protein-protein interfaces. Proc Natl Acad Sci 102: 15447-15452. doi:10.1073/pnas.0505425102

Hall KB, Kranz JK. 1999. Nitrocellulose filter binding for determination of dissociation constants. In RNA-protein interaction protocols (ed. Haynes SR), pp. 105-114. Humana Press, Totowa, NJ.

Hardin JW, Hu YX, McKay DB. 2010. Structure of the RNA binding domain of a DEAD-box helicase bound to its ribosomal RNA target reveals a novel mode of recognition by an RNA recognition motif. J Mol Biol 402: 412-427. doi:10.1016/j.jmb.2010.07.040

Hauenstein S, Zhang CM, Hou YM, Perona JJ. 2004. Shape-selective RNA recognition by cysteinyl-tRNA synthetase. Nat Struct Mol Biol 11: 1134-1141. doi:10.1038/nsmb849

Hellman LM, Fried MG. 2007. Electrophoretic mobility shift assay (EMSA) for detecting protein-nucleic acid interactions. Nat Protoc 2: 1849-1861. doi:10.1038/nprot.2007.249

Holm L, Laakso LM. 2016. Dali server update. Nucleic Acids Res 44: W351-W355. doi:10.1093/nar/gkw357

Horton N, Lewis M. 1992. Calculation of the free energy of association for protein complexes. Protein Sci 1: 169-181. doi:10.1002/pro .5560010117

Hou T, Wang J, LiY, Wang W. 2011. Assessing the performance of the MM/PBSA and MM/GBSA methods. 1. The accuracy of binding free energy calculations based on molecular dynamics simulations. J Chem Inf Model 51: 69-82. doi:10.1021/ci100275a

Huang SY, Zou X. 2013. A nonredundant structure dataset for benchmarking protein-RNA computational docking. J Comput Chem 34: 311-318. doi:10.1002/jcc.23149

Huang SY, Zou X. 2014. A knowledge-based scoring function for protein-RNA interactions derived from a statistical mechanics-based iterative method. Nucleic Acids Res 42: e55. doi:10.1093/nar/ gku077

Huang DB, Vu D, Cassiday LA, Zimmerman JM, Maher LJ III, Ghosh G. 2003. Crystal structure of NF-kB (p50) $)_{2}$ complexed to a high-affinity RNA aptamer. Proc Natl Acad Sci 100: 9268-9273. doi:10 .1073/pnas.1632011100

Huang Y, Liu S, Guo D, Li L, Xiao Y. 2013. A novel protocol for threedimensional structure prediction of RNA-protein complexes. Sci Rep 3: 1887. doi:10.1038/srep01887

Huang Y, Li H, Xiao Y. 2016. Using 3dRPC for RNA-protein complex structure prediction. Biophys Rep 2: 95-99. doi:10.1007/s41048017-0034-y

Hubbard SJ, Thornton JM. 1993. NACCESS: program for calculating accessibilities. Department of Biochemistry and Molecular Biology, University College, London.

Iwakiri J, Tateishi H, Chakraborty A, Patil P, Kenmochi N. 2012. Dissecting the protein-RNA interface: the role of protein surface shapes and RNA secondary structures in protein-RNA recognition. Nucleic Acids Res 40: 3299-3306. doi:10.1093/nar/gkr1225

Janin J. 1995. Protein-protein recognition. Prog Biophys Mol Biol 64: 145-166. doi:10.1016/S0079-6107(96)00001-6

Janin J. 2014. A minimal model of protein-protein binding affinities. Protein Sci 23: 1813-1817. doi:10.1002/pro.2560

Janin J, Bahadur RP. 2008. Relating macromolecular function and association: the structural basis of protein-DNA and RNA recognition. Cell Mol Bioeng 1: 327-338. doi:10.1007/s12195-0080032-8

Janin J, Bahadur RP, Chakrabarti P. 2008. Protein-protein interaction and quaternary structure. $Q$ Rev Biophys 41: 133-180. doi:10 $.1017 /$ S0033583508004708

Jayaram B, Jain T. 2004. The role of water in protein-DNA recognition. Annu Rev Biophys Biomol Struct 33: 343-361. doi:10.1146/ annurev.biophys.33.110502.140414 
Jia MZ, Horita S, Nagata K, Tanokura M. 2010. An archaeal Dim2-like protein, aDim2p, forms a ternary complex with a/elF2 $\alpha$ and the $3^{\prime}$ end fragment of 16S rRNA. J Mol Biol 398: 774-785. doi:10.1016/j .jmb.2010.03.055

Jones S. 2001. Protein-RNA interactions: a structural analysis. Nucleic Acids Res 29: 943-954. doi:10.1093/nar/29.4.943

Jones S, Thornton JM. 1996. Principles of protein-protein interactions. Proc Natl Acad Sci 93: 13-20. doi:10.1073/pnas.93.1.13

Kastritis PL, Bonvin AM. 2010. Are scoring functions in protein-protein docking ready to predict interactomes? Clues from a novel binding affinity benchmark. J Proteome Res 9: 2216-2225. doi:10.1021/ pr9009854

Kastritis PL, Bonvin AM. 2013. On the binding affinity of macromolecular interactions: daring to ask why proteins interact. J R Soc Interface 10: 20120835. doi:10.1098/rsif.2012.0835

Kastritis PL, Moal IH, Hwang H, Weng Z, Bates PA, Bonvin AM, Janin J. 2011. A structure-based benchmark for protein-protein binding affinity. Protein Sci 20: 482-491. doi:10.1002/pro.580

Katsamba PS, Park S, Laird-Offringa IA. 2002. Kinetic studies of RNAprotein interactions using surface plasmon resonance. Methods 26: 95-104. doi:10.1016/S1046-2023(02)00012-9

Kauzmann W. 1959. Some factors in the interpretation of protein denaturation. Adv Protein Chem 14: 1-63. doi:10.1016/S00653233(08)60608-7

Kim R, Skolnick J. 2008. Assessment of programs for ligand binding affinity prediction. J Comput Chem 29: 1316-1331. doi:10 $.1002 /$ jcc.20893

Klotz IM. 1985. Ligand-receptor interactions: facts and fantasies. Q Rev Biophys 18: 227-259. doi:10.1017/S0033583500000354

Kollman P. 1993. Free-energy calculations-applications to chemical and biochemical phenomena. Chem Rev 93: 2395-2417. doi:10 $.1021 / \mathrm{cr00023a004}$

Krüger DM, Neubacher S, Grossmann TN. 2018. Protein-RNA interactions: structural characteristics and hotspot amino acids. RNA 24: 1457-1465. doi:10.1261/rna.066464.118

Ladbury JE, Chowdhry BZ. 1996. Sensing the heat: the application of isothermal titration calorimetry to thermodynamic studies of biomolecular interactions. Chem Biol 3: 791-801. doi:10.1016/ S1074-5521(96)90063-0

Laskowski RA. 1995. SURFNET: a program for visualizing molecular surfaces, cavities, and intermolecular interactions. J Mol Graph 13: 323-330. 307-328. doi:10.1016/0263-7855(95)00073-9

Lawrence MC, Colman PM. 1993. Shape complementarity at protein/ protein interfaces. J Mol Biol 234: 946-950. doi:10.1006/jmbi .1993.1648

Lee B, Richards FM. 1971. The interpretation of protein structures: estimation of static accessibility. J Mol Biol 55: 379-400. doi:10 .1016/0022-2836(71)90324-X

Le Grand S, Götz AW, Walker RC. 2013. SPFP: speed without compromise-a mixed precision model for GPU accelerated molecular dynamics simulations. Comput Phys Commun 184: 374-380. doi:10 .1016/j.cpc.2012.09.022

Li Z, Lazaridis T. 2007. Water at biomolecular binding interfaces. Phys Chem Chem Phys 9: 573-581. doi:10.1039/B612449F

Li X, Ranjith-Kumar CT, Brooks MT, Dharmaiah S, Herr AB, Kao C, Li P. 2009. The RIG-I-like receptor LGP2 recognizes the termini of double-stranded RNA. J Biol Chem 284: 13881-13891. doi:10.1074/ jbc.M900818200

Li CH, Cao LB, Su JG, Yang YX, Wang CX. 2012. A new residue-nucleotide propensity potential with structural information considered for discriminating protein-RNA docking decoys. Proteins 80: 1424. doi:10.1002/prot.23117

Liu Z, Li Y, Han L, Li J, Liu J, Zhao Z, Nie W, Liu Y, Wang R. 2015. PDBwide collection of binding data: current status of the PDBbind da- tabase. Bioinformatics 31: 405-412. doi:10.1093/bioinformatics/ btu626

Liu L, Xiong Y, Gao H, Wei DQ, Mitchell JC, Zhu X. 2018. dbAMEPNI: a database of alanine mutagenic effects for protein-nucleic acid interactions. Database (Oxford) 2018: bay034. doi:10.1093/data base/bay034

Locatelli GA, Spadari S, Maga G. 2002. Hepatitis C virus NS3 ATPase/ helicase: an ATP switch regulates the cooperativity among the different substrate binding sites. Biochemistry 41: 10332-10342. doi:10.1021/bi026082g

Lunde BM, Hörner M, Meinhart A. 2011. Structural insights into cis element recognition of non-polyadenylated RNAs by the Nab3RRM. Nucleic Acids Res 39: 337-346. doi:10.1093/nar/gkq751

Ma XH, Wang CX, Li CH, Chen WZ. 2002. A fast empirical approach to binding free energy calculations based on protein interface information. Protein Eng 15: 677-681. doi:10.1093/protein/15.8.677

Maier JA, Martinez C, Kasavajhala K, Wickstrom L, Hauser KE, Simmerling C. 2015. ff14SB: improving the accuracy of protein side chain and backbone parameters from ff99SB. J Chem Theory Comput 11: 3696-3713. doi:10.1021/acs.jctc.5b00255

Martinez A, Opperman T, Richardson JP. 1996. Mutational analysis and secondary structure model of the RNP1-like sequence motif of transcription termination factor Rho. J Mol Biol 257: 895-908. doi:10.1006/jmbi.1996.0210

McDonald IK, Thornton JM. 1994. Satisfying hydrogen bonding potential in proteins. J Mol Biol 238: 777-793. doi:10.1006/jmbi .1994 .1334

Miller MT, Higgin JJ, Hall TM. 2008. Basis of altered RNA-binding specificity by PUF proteins revealed by crystal structures of yeast Puf4p. Nat Struct Mol Biol 15: 397-402. doi:10.1038/nsmb .1390

Mitchell JBO, Laskowski RA, Alex A, Forster MJ, Thornton JM. 1999. BLEEP-potential of mean force describing protein-ligand interactions: II. Calculation of binding energies and comparison with experimental data. J Comput Chem 20: 1177-1185. doi:10 .1002/(SICI)1096-987X(199908)20:11<1177::AID-JCC8>3.0.CO ;2-0

Moal IH, Agius R, Bates PA. 2011. Protein-protein binding affinity prediction on a diverse set of structures. Bioinformatics 27: 30023009. doi:10.1093/bioinformatics/btr513

Mukherjee S, Bahadur RP. 2018. An account of solvent accessibility in protein-RNA recognition. Sci Rep 8: 10546. doi:10.1038/s41598018-28373-2

Mukherjee S, Nithin C, Divakaruni Y, Bahadur RP. 2019. Dissecting water binding sites at protein-protein interfaces: a lesson from the atomic structures in the Protein Data Bank. J Biomol Struct Dyn 37: 1204-1219. doi:10.1080/07391102.2018.1453379

Murphy KP, Xie D, Garcia KC, Amzel LM, Freire E. 1993. Structural energetics of peptide recognition: angiotensin II/antibody binding. Proteins 15: 113-120. doi:10.1002/prot.340150203

Nadassy K, Wodak SJ, Janin J. 1999. Structural features of protein-nucleic acid recognition sites. Biochemistry 38: 1999-2017. doi:10 $.1021 /$ bi982362d

Nithin C, Mukherjee S, Bahadur RP. 2017. A non-redundant proteinRNA docking benchmark version 2.0. Proteins 85: 256-267. doi:10.1002/prot.25211

Nithin C, Ghosh P, Bujnicki JM. 2018. Bioinformatics tools and benchmarks for computational docking and 3D structure prediction of RNA-protein complexes. Genes (Basel) 9: E432. doi:10.3390/ genes 9090432

Oddone A, Lorentzen E, Basquin J, Gasch A, Rybin V, Conti E, Sattler M. 2007. Structural and biochemical characterization of the yeast exosome component Rrp40. EMBO Rep 8: 63-69. doi:10.1038/sj.embor.7400856 
Oehler S, Alex R, Barker A. 1999. Is nitrocellulose filter binding really a universal assay for protein-DNA interactions? Anal Biochemi 268: 330-336. doi:10.1006/abio.1998.3056

Okabe M, Tomita K, Ishitani R, Ishii R, Takeuchi N, Arisaka F, Nureki O, Yokoyama S. 2003. Divergent evolutions of trinucleotide polymerization revealed by an archaeal CCA-adding enzyme structure. EMBO J 22: 5918-5927. doi:10.1093/emboj/cdg563

Pagano JM, Clingman CC, Ryder SP. 2011. Quantitative approaches to monitor protein-nucleic acid interactions using fluorescent probes. RNA 17: 14-20. doi:10.1261/rna.2428111

Pan H, Agarwalla S, Moustakas DT, Finer-Moore J, Stroud RM. 2003. Structure of tRNA pseudouridine synthase TruB and its RNA complex: RNA recognition through a combination of rigid docking and induced fit. Proc Natl Acad Sci 100: 12648-12653. doi:10.1073/ pnas. 2135585100

Pan Y, Wang Z, Zhan W, Deng L. 2018. Computational identification of binding energy hot spots in protein-RNA complexes using an ensemble approach. Bioinformatics 34: 1473-1480. doi:10.1093/bio informatics/btx822

Pauling L, Pressman D. 1945. The serological properties of simple substances. IX. Hapten inhibition of precipitation of antisera homologous to the $o_{-}, m-$, and $p$-azophenylarsonic acid groups. $J$ Am Chem Soc 67: 1003-1012. doi:10.1021/ja01222a033

Pérez-Cano L, Jiménez-García B, Fernández-Recio J. 2012. A proteinRNA docking benchmark (II): extended set from experimental and homology modeling data. Proteins 80: 1872-1882. doi:10.1002/ prot.24075

Raymond DD, Piper ME, Gerrard SR, Skiniotis G, Smith JL. 2012. Phleboviruses encapsidate their genomes by sequestering RNA bases. Proc Natl Acad Sci 109: 19208-19213. doi:10.1073/pnas .1213553109

Reichmann D, Phillip Y, Carmi A, Schreiber G. 2008. On the contribution of water-mediated interactions to protein-complex stability. Biochemistry 47: 1051-1060. doi:10.1021/bi7019639

Rio DC. 2012. Filter-binding assay for analysis of RNA-protein interactions. Cold Spring Harb Protoc 2012: 1078-1081.

Rodier F, Bahadur RP, Chakrabarti P, Janin J. 2005. Hydration of protein-protein interfaces. Proteins 60: 36-45. doi:10.1002/prot .20478

Rozhdestvensky TS, Tang TH, Tchirkova IV, Brosius J, Bachellerie JP, Huttenhofer A. 2003. Binding of L7Ae protein to the K-turn of archaeal snoRNAs: a shared RNA binding motif for C/D and H/ACA box snoRNAs in Archaea. Nucleic Acids Res 31: 869-877. doi:10 $.1093 / \mathrm{nar} / \mathrm{gkg} 175$

Ryder SP, Recht MI, Williamson JR. 2008. Quantitative analysis of protein-RNA interactions by gel mobility shift. Methods Mol Biol 488: 99-115. doi:10.1007/978-1-60327-475-3_7

Sachs R, Max KE, Heinemann U, Balbach J. 2012. RNA single strands bind to a conserved surface of the major cold shock protein in crystals and solution. RNA 18: 65-76. doi:10.1261/rna.02809212

Salomon-Ferrer R, Götz AW, Poole D, Le Grand S, Walker RC. 2013. Routine microsecond molecular dynamics simulations with AMBER on GPUs. 2. Explicit solvent particle mesh Ewald. J Chem Theory Comput 9: 3878-3888. doi:10.1021/ct400314y

Sashital DG, Jinek M, Doudna JA. 2011. An RNA-induced conformational change required for CRISPR RNA cleavage by the endoribonuclease Cse3. Nat Struct Mol Biol 18: 680-687. doi:10.1038/ nsmb. 2043

Schmidt M, Lipson H. 2009. Distilling free-form natural laws from experimental data. Science 324: 81-85. doi:10.1126/science .1165893

Schuck P, Zhao H. 2010. The role of mass transport limitation and surface heterogeneity in the biophysical characterization of macromolecular binding processes by SPR biosensing. Methods Mol Biol 627: 15-54. doi:10.1007/978-1-60761-670-2_2
Schumacher MA, Pearson RF, Moller T, Valentin-Hansen P, Brennan RG. 2002. Structures of the pleiotropic translational regulator $\mathrm{Hfq}$ and an Hfq-RNA complex: a bacterial Sm-like protein. EMBO J 21: 3546-3556. doi:10.1093/emboj/cdf322

Selvaraj S, Kono H, Sarai A. 2002. Specificity of protein-DNA recognition revealed by structure-based potentials: symmetric/asymmetric and cognate/non-cognate binding. J Mol Biol 322: 907-915. doi:10.1016/S0022-2836(02)00846-X

Setny P, Zacharias M. 2011. A coarse-grained force field for proteinRNA docking. Nucleic Acids Res 39: 9118-9129. doi:10.1093/ nar/gkr636

Sim AY, Minary P, Levitt M. 2012. Modeling nucleic acids. Curr Opin Struct Biol 22: 273-278. doi:10.1016/j.sbi.2012.03.012

Singh M, Wang Z, Koo BK, Patel A, Cascio D, Collins K, Feigon J. 2012. Structural basis for telomerase RNA recognition and RNP assembly by the holoenzyme La family protein p65. Mol Cell 47: 1626. doi:10.1016/j.molcel.2012.05.018

Soler N, Fourmy D, Yoshizawa S. 2007. Structural insight into a molecular switch in tandem winged-helix motifs from elongation factor SelB. J Mol Biol 370: 728-741. doi:10.1016/j.jmb.2007.05.001

Spierer $P$, Bogdanov AA, Zimmermann RA. 1978. Parameters for the interaction of ribosomal proteins L5, L18, and L25 with 5S RNA from Escherichia coli. Biochemistry 17: 5394-5398. doi:10.1021/ bi00618a012

Šponer J, Bussi G, Krepl M, Banáš P, Bottaro S, Cunha RA, Gil-Ley A, Pinamonti G, Poblete $S$, Jurečka P, et al. 2018. RNA structural dynamics as captured by molecular simulations: a comprehensive overview. Chem Rev 118: 4177-4338. doi:10.1021/acs.chemrev $.7 \mathrm{~b} 00427$

Stein AJ, Fuchs G, Fu C, Wolin SL, Reinisch KM. 2005. Structural insights into RNA quality control: the Ro autoantigen binds misfolded RNAs via its central cavity. Cell 121: 529-539. doi:10 .1016/j.cell.2005.03.009

Su Y, Zhou A, Xia X, Li W, Sun Z. 2009. Quantitative prediction of protein-protein binding affinity with a potential of mean force considering volume correction. Protein Sci 18: 2550-2558. doi:10.1002/ pro. 257

Sun YX, Kollman PA. 1995. Hydrophobic solvation of methane and nonbond parameters of the Tip3p water model. J Comput Chem 16: 1164-1169. doi:10.1002/jcc.540160910

Teplova M, Patel DJ. 2008. Structural insights into RNA recognition by the alternative-splicing regulator muscleblind-like MBNL1. Nat Struct Mol Biol 15: 1343-1351. doi:10.1038/nsmb.1519

Teplova M, Song J, Gaw HY, Teplov A, Patel DJ. 2010. Structural insights into RNA recognition by the alternate-splicing regulator CUG-binding protein 1. Structure 18: 1364-1377. doi:10.1016/j .str.2010.06.018

Teplova M, Wohlbold L, Khin NW, Izaurralde E, Patel DJ. 2011. Structure-function studies of nucleocytoplasmic transport of retroviral genomic RNA by mRNA export factor TAP. Nat Struct Mol Biol 18: 990-998. doi:10.1038/nsmb.2094

Terribilini M. 2008. "Computational analysis and prediction of protein-RNA interactions." PhD thesis, lowa State University, lowa.

Teyra J, Pisabarro MT. 2007. Characterization of interfacial solvent in protein complexes and contribution of wet spots to the interface description. Proteins 67: 1087-1095. doi:10.1002/prot.21394

Tian F, Lv Y, Yang L. 2012. Structure-based prediction of protein-protein binding affinity with consideration of allosteric effect. Amino Acids 43: 531-543. doi:10.1007/s00726-011-1101-1

Tishchenko S, Nikonova E, Nikulin A, Nevskaya N, Volchkov S, Piendl W, Garber M, Nikonov S. 2006. Structure of the ribosomal protein L1-mRNA complex at $2.1 \AA$ resolution: common features of crystal packing of L1-RNA complexes. Acta Crystallogr D Biol Crystallogr 62: 1545-1554. doi:10.1107/S0907444906041655 
Tomita K, Ishitani R, Fukai S, Nureki O. 2006. Complete crystallographic analysis of the dynamics of CCA sequence addition. Nature 443: 956-960. doi:10.1038/nature05204

Treger M, Westhof E. 2001. Statistical analysis of atomic contacts at RNA-protein interfaces. J Mol Recognit 14: 199-214. doi:10 $.1002 / j m r .534$

Tu C, Zhou X, Tarasov SG, Tropea JE, Austin BP, Waugh DS, Court DL, $\mathrm{Ji}$ X. 2011. The Era GTPase recognizes the GAUCACCUCC sequence and binds helix 45 near the $3^{\prime}$ end of $16 \mathrm{~S}$ rRNA. Proc Natl Acad Sci 108: 10156-10161. doi:10.1073/pnas.1017679108

Tuszynska I, Bujnicki JM. 2011. DARS-RNP and QUASI-RNP: new statistical potentials for protein-RNA docking. BMC Bioinformatics 12: 348. doi:10.1186/1471-2105-12-348

Uter NT, Gruic-Sovulj I, Perona JJ. 2005. Amino acid-dependent transfer RNA affinity in a class I aminoacyl-tRNA synthetase. J Biol Chem 280: 23966-23977. doi:10.1074/jbc.M414259200

Vajda S, Weng Z, Rosenfeld R, DeLisi C. 1994. Effect of conformational flexibility and solvation on receptor-ligand binding free energies. Biochemistry 33: 13977-13988. doi:10.1021/bi00251a004

Vivian JT, Callis PR. 2001. Mechanisms of tryptophan fluorescence shifts in proteins. Biophys J 80: 2093-2109. doi:10.1016/S00063495(01)76183-8

Vreven T, Moal IH, Vangone A, Pierce BG, Kastritis PL, Torchala M, Chaleil R, Jiménez-García B, Bates PA, Fernandez-Recio J, et al. 2015. Updates to the integrated protein-protein interaction benchmarks: docking benchmark version 5 and affinity benchmark version 2. J Mol Biol 427: 3031-3041. doi:10.1016/j.jmb.2015.07 .016

Walden WE, Selezneva A, Volz K. 2012. Accommodating variety in iron-responsive elements: crystal structure of transferrin receptor 1 B IRE bound to iron regulatory protein 1. FEBS Lett 586: 3235. doi:10.1016/j.febslet.2011.11.018

Webb B, Sali A. 2016. Comparative protein structure modeling using MODELLER. Curr Protoc Protein Sci 86: 2.9.1-2.9.37. doi:10 $.1002 /$ cpps.20

White R, Rusconi C, Scardino E, Wolberg A, Lawson J, Hoffman M, Sullenger B. 2001. Generation of species cross-reactive aptamers using "Toggle" SELEX. Mol Ther 4: 567-573. doi:10.1006/mthe .2001 .0495

Xu D, Tsai CJ, Nussinov R. 1997. Hydrogen bonds and salt bridges across protein-protein interfaces. Protein Eng 10: 999-1012. doi:10.1093/protein/10.9.999
Xue LC, Rodrigues JP, Kastritis PL, Bonvin AM, Vangone A. 2016. PRODIGY: a web server for predicting the binding affinity of protein-protein complexes. Bioinformatics 32: 3676-3678.

Yang X, Gérczei T, Glover LT, Correll CC. 2001. Crystal structures of restrictocin-inhibitor complexes with implications for RNA recognition and base flipping. Nat Struct Biol 8: 968-973. doi:10.1038/ nsb1101-968

Yang Y, Wang Q, Guo D. 2008. A novel strategy for analyzing RNAprotein interactions by surface plasmon resonance biosensor. Mol Biotechnol 40: 87-93. doi:10.1007/s12033-008-9066-3

Yang Q, Gilmartin GM, Doublie S. 2010. Structural basis of UGUA recognition by the Nudix protein $\mathrm{CFI}_{\mathrm{m}} 25$ and implications for a regulatory role in mRNA 3' processing. Proc Natl Acad Sci 107: 10062 10067. doi:10.1073/pnas. 1000848107

Yang X, Li H, Huang Y, Liu S. 2013. The dataset for protein-RNA binding affinity. Protein Sci 22: 1808-1811. doi:10.1002/pro.2383

Yang Y, Zhao H, Wang J, Zhou Y. 2014. SPOT-Seq-RNA: predicting protein-RNA complex structure and RNA-binding function by fold recognition and binding affinity prediction. In Protein structure prediction (ed. Kihara D), pp. 119-130. Springer, New York.

Ye JD, Tereshko V, Frederiksen JK, Koide A, Fellouse FA, Sidhu SS, Koide S, Kossiakoff AA, Piccirilli JA. 2008. Synthetic antibodies for specific recognition and crystallization of structured RNA. Proc Natl Acad Sci 105: 82-87. doi:10.1073/pnas.0709082105

Yoshizawa S, Rasubala L, Ose T, Kohda D, Fourmy D, Maenaka K. 2005. Structural basis for mRNA recognition by elongation factor SelB. Nat Struct Mol Biol 12: 198-203. doi:10.1038/nsmb890

Zgarbová $M$, Otyepka $M$, Šponer J, Mládek A, Banáš $P$, Cheatham TE III, Jurečka P. 2011. Refinement of the Cornell et al. nucleic acids force field based on reference quantum chemical calculations of glycosidic torsion profiles. J Chem Theory Comput 7: 2886-2902. doi:10.1021/ct200162x

Zhang C, Liu S, Zhu Q, Zhou Y. 2005. A knowledge-based energy function for protein-ligand, protein-protein, and protein-DNA complexes. J Med Chem 48: 2325-2335. doi:10.1021/jm049314d

Zhao H, Yang Y, Zhou Y. 2011. Structure-based prediction of RNAbinding domains and RNA-binding sites and application to structural genomics targets. Nucleic Acids Res 39: 3017-3025. doi:10 $.1093 /$ nar/gkq1266

Zheng S, Robertson TA, Varani G. 2007. A knowledge-based potential function predicts the specificity and relative binding energy of RNA-binding proteins. FEBS J 274: 6378-6391. doi:10.1111/j $.1742-4658.2007 .06155 . x$ 

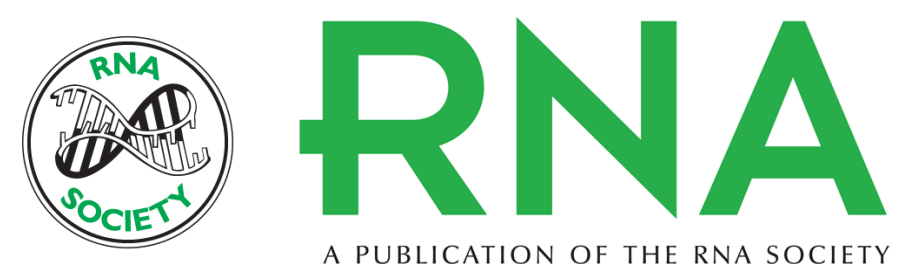

A PUBLICATION OF THE RNA SOCIETY

\section{A structure-based model for the prediction of protein-RNA binding affinity}

Chandran Nithin, Sunandan Mukherjee and Ranjit Prasad Bahadur

RNA 2019 25: 1628-1645 originally published online August 8, 2019

Access the most recent version at doi:10.1261/rna.071779.119

\section{Supplemental http://rnajournal.cshlp.org/content/suppl/2019/08/08/rna.071779.119.DC1 \\ Material}

References This article cites 151 articles, 17 of which can be accessed free at: http://rnajournal.cshlp.org/content/25/12/1628.full.html\#ref-list-1

Creative This article is distributed exclusively by the RNA Society for the first 12 months after the Commons

License full-issue publication date (see http://rnajournal.cshlp.org/site/misc/terms.xhtml). After 12 months, it is available under a Creative Commons License (Attribution-NonCommercial 4.0 International), as described at http://creativecommons.org/licenses/by-nc/4.0/.

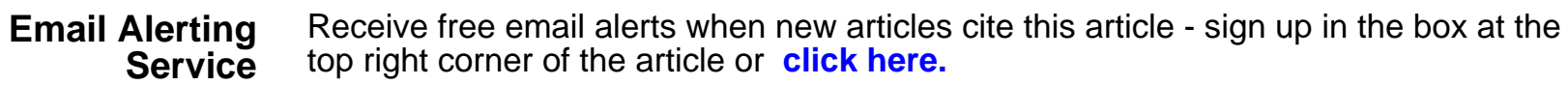

